\title{
BID regulates AIF-mediated caspase-independent necroptosis by promoting BAX activation
}

\author{
L Cabon ${ }^{1,2,3}$, P Galán-Malo ${ }^{1,2,3,8}$, A Bouharrour ${ }^{1,2,3,8}$, L Delavallée ${ }^{1,2,3}$, M-N Brunelle-Navas ${ }^{1,2,3}$, HK Lorenzo ${ }^{4,5,6}$, A Gross ${ }^{7}$ \\ and SA Susin $\sin ^{\star 1,2,3}$
}

Alkylating DNA-damage agents such as N-methyl-N'-nitro-N'-nitrosoguanidine (MNNG) trigger necroptosis, a newly defined form of programmed cell death (PCD) managed by receptor interacting protein kinases. This caspase-independent mode of cell death involves the sequential activation of poly(ADP-ribose) polymerase-1 (PARP-1), calpains, BAX and AIF, which redistributes from mitochondria to the nucleus to promote chromatinolysis. We have previously demonstrated that the BAX-mediated mitochondrial release of AIF is a critical step in MNNG-mediated necroptosis. However, the mechanism regulating BAX activation in this PCD is poorly understood. Employing mouse embryonic knockout cells, we reveal that BID controls BAX activation in AIF-mediated necroptosis. Indeed, BID is a link between calpains and BAX in this mode of cell death. Therefore, even if PARP-1 and calpains are activated after MNNG treatment, BID genetic ablation abolishes both BAX activation and necroptosis. These PCD defects are reversed by reintroducing the BID-wt CDNA into the $B I D^{-/}$cells. We also demonstrate that, after MNNG treatment, BID is directly processed into tBID by calpains. In this way, calpain non-cleavable BID proteins (BID-G70A or BID- $\triangle 68-71$ ) are unable to promote BAX activation and necroptosis. Once processed, tBID localizes in the mitochondria of MNNG-treated cells, where it can facilitate BAX activation and PCD. Altogether, our data reveal that, as in caspase-dependent apoptosis, BH3only proteins are key regulators of caspase-independent necroptosis.

Cell Death and Differentiation (2012) 19, 245-256; doi:10.1038/cdd.2011.91; published online 8 July 2011

When and how a cell dies is one of the essential questions to understand the biology of the cell. A cell is considered dead when the integrity of its plasma membrane is compromised, when its fragments are engulfed by an adjacent or a professional cell or when its components, including the nucleus, are fragmented. It is more complicated to outline how a cell could die. Historically, two major types of cell death have been distinguished: apoptosis, a controlled or programmed cell death (PCD), and necrosis, an uncontrolled or accidental death. ${ }^{1}$ Cell biologists have particularly focused their attention on apoptotic PCD, helping to characterize it at both genetic and biochemical levels. ${ }^{2}$ Fascinatingly, the use of apoptotic inhibitors or cells that are deficient in key apoptotic molecules has revealed the existence of new PCD pathways. As a consequence, active forms of cell death started to be referred to as caspase-dependent or caspase-independent. ${ }^{3}$ More recently, it has been accepted that necrosis is more than an unregulated type of death. Indeed, a cell can use different mechanisms/pathways with underlying apoptotic or necrotic features to accomplish its proper demise. ${ }^{4}$
The analysis of the tumor necrosis factor (TNF) signaling path has shed new light on the existence of PCD pathways with necrotic features. When TNF binds its receptor, two ways can be engaged: (i) caspase-dependent apoptosis, mediated by activation of caspase-8, and (ii) something similar to necrosis, which is caspase-independent, and is mediated by receptor interacting protein (RIP) kinases, RIP1 and RIP3. Pharmacological and genetic approaches have revealed a panoply of modulators of TNF-induced necroptosis, a term used to define this finely regulated form of cell death. ${ }^{5}$ Strikingly, PCD by necroptosis (programmed necrosis) is also induced by high doses of the alkylating DNA-damage agent $\mathrm{N}$-methyl-N'-nitro- $\mathrm{N}^{\prime}$-nitrosoguanidine (MNNG). ${ }^{6}$ This necroptotic process, which is also regulated by the kinase RIP $1,{ }^{7}$ is executed by the harmonic activation of poly(ADPribose) polymerase-1 (PARP-1), $\mathrm{Ca}^{2+}$-dependent calpain Cys-proteases, and the pro-apoptotic BCL-2 member BAX ${ }^{8} \mathrm{~A}$ key consequence of the activation of these three enzymes is the mitochondrial release of truncated AIF (tAIF), a major effector in caspase-independent PCD. ${ }^{9-13}$ Cytosolic tAIF

\footnotetext{
${ }^{1}$ INSERM U872, Mort cellulaire programmée et physiopathologie des cellules tumorales, Equipe 19, Centre de Recherche des Cordeliers, Paris, France; ${ }^{2}$ Université Pierre et Marie Curie-Sorbonne Universités, UMRS 872, Paris, France; ${ }^{3}$ Université Paris Descartes, UMRS 872, Paris, France; ${ }^{4}$ Faculté de Medécine, Université Paris 11 , Le Kremlin-Bicêtre, France; ${ }^{5} \mathrm{CHU}$ Bicêtre, Service de Néphrologie, Le Kremlin-Bicêtre, France; ${ }^{6}$ INSERM U1014, Villejuif, France and ${ }^{7}$ Department of Biological Regulation, Weizmann Institute of Science, Rehovot, Israel

${ }^{*}$ Corresponding author: SA Susin, INSERM U872, Mort cellulaire programmée et physiopathologie des cellules tumorales, Equipe 19, Centre de Recherche des Cordeliers, 15 rue de l'Ecole de Médecine, 75006 Paris, France. Tel: + 3314427 9070; Fax: + 3314427 9036; E-mail: santos.susin@ crc.jussieu.fr

${ }^{8}$ These authors contributed equally to this work. Keywords: AIF; BAX; BID; calpains; necroptosis

Abbreviations: AIF, Apoptosis-inducing factor; BAD, Bcl-2-associated death promoter; BAX, Bcl-2-associated X protein; BAK, Bcl-2 homologous antagonist/killer; BCL-XL, B-cell lymphoma-extra large; BCL-2, B-cell lymphoma 2; BCL-W, Bcl-2-like protein 2; BID, BH3 interacting domain death agonist; BIM, Bcl-2 interacting mediator of cell death; BNIP3, BCL2/adenovirus E1B 19 kDa protein-interacting protein 3; BMF, Bcl-2-modifying factor; CHX, Cycloheximide; DMEM, Dulbecco's Modified Eagle's Medium; DMSO, Dimethyl sulfoxide; FCS, Fetal calf serum; JNK1, c-Jun NH2-terminal kinase 1; MCL-1, Myeloid cell leukemia sequence 1; MTCH2/ MIMP, Mitochondrial carrier homolog 2; Q-VD.OPh, Gln-Val-Asp(non-Omethylated)-Oph

Received 23.5.11; accepted 24.5.11; Edited by P Bouillet; published online 08.7.11
} 
rapidly redistributes to the nuclear compartment where, assisted by $\gamma \mathrm{H} 2 \mathrm{AX}$ and cyclophilin A (CypA), it promotes chromatinolysis and cell-viability loss. ${ }^{14,15}$

Among the features of MNNG-induced necroptosis, the implication of BCL-2 family members appears as a milestone. The BCL-2 set of proteins is distributed in three subgroups according to their properties. ${ }^{16}$ The first subfamily comprises $B C L-X L, B C L-2, B C L-W$ and $M C L-1$. They contain three or four $\mathrm{BCL}-2$ homology $(\mathrm{BH})$ domains that are known to be necessary for their anti-apoptotic function. Through their interactions with other BCL-2 members, they negatively regulate the mitochondrial release of pro-apoptotic proteins. ${ }^{16}$ The second subgroup corresponds to pro-apoptotic proteins, such as BAX and BAK, which are able to form pores or associate with pore-forming proteins in the outer mitochondrial membrane. This process induces mitochondrial permeabilization and the release of cell death-promoting proteins. ${ }^{17}$ The third BCL-2 subfamily regroups the proteins that only have a short $\mathrm{BH} 3$ domain. These $\mathrm{BH} 3-o n l y$ proteins interact with both anti- and pro-apoptotic $\mathrm{BCL}-2$ members to induce PCD. ${ }^{16}$

In MNNG-induced necroptosis, the key role of the two first subgroups of the BCL-2 family has been recently established: BCL-2 and BAX manage the mitochondrial release of tAIF. ${ }^{8}$ However, a pivotal question remains: How is BAX activated here? With the help of a panel of murine embryonic fibroblast (MEF) knockout cells, the aim of the present work was to examine this issue. This approach revealed that, through its pro-apoptotic function, BID regulates BAX activation and PCD. Cleaved into tBID via a calpain cleavage at Gly70, this $\mathrm{BH}$-only protein is indeed the link between calpains and BAX in MNNG-mediated necroptosis.

\section{Results}

MNNG-induced caspase-independent necroptosis: a highly regulated PCD process. Treatment of MEFs with MNNG induces necroptosis, a RIP1 kinase-dependent mode of PCD modulated by necrostatin-1 (Supplementary Figure 1). ${ }^{5-7}$ This type of cell death, enabled here by the action of PARP-1, is a caspase-independent process with significant alterations detected as soon as $6 \mathrm{~h}$ of MNNG treatment (Figure 1a). ${ }^{8,14}$ As in staurosporine (STS)-induced caspase-dependent apoptosis (our positive control), MNNG-treated cells undergo Annexin V-detectable phosphatidylserine (PS) exposure. However, in contrast to STS-induced PCD, MNNG treatment provokes a double Annexin V/PI(propidium iodide)-positive labeling (Figure 1a), which is indeed a hallmark of this type of PCD. ${ }^{18}$ MNNGinduced death is also characterized by the sequential activation of calpains and BAX (Figures $1 b$ and c). ${ }^{8}$ Once in mitochondria, BAX provokes a mitochondrial damage that is accompanied by the release of tAIF, the truncated form of AIF, to the cytosol and nucleus (Figures $1 \mathrm{~d}$ and e) ${ }^{8,14}$ In the nucleus, this apoptogenic protein generates TUNELdetectable $3^{\prime}-\mathrm{OH}$ DNA breaks in DNA (Figure 1f). Altogether, these events represent the biochemical hallmarks of MNNG-mediated necroptosis. . $^{814}$

BAX activation is critical in MNNG-induced necroptosis. The presence of tAIF in extramitochondrial compartments is vital in the PCD process triggered by MNNG. As demonstrated by BAX genetic ablation, tAIF release and necroptosis are specifically controlled by the mitochondrial action of activated BAX (Figures $2 a$ and $b$ ). ${ }^{8}$ But, how is BAX activated in necroptosis? We have previously described that BAX activation depends on calpain activity. ${ }^{8}$ Thus, a first possibility is that calpains cleave inactive BAX at Asp33 (D33) to yield a p18 active protein. ${ }^{19}$ By an immunoblotting approach, we thus tested whether the treatment of MEFs with MNNG generated the $\mathrm{p} 18$ active form of BAX. As depicted in Figure $2 \mathrm{c}$, in contrast to STS, BAX does not become cleaved at D33 even $9 \mathrm{~h}$ after MNNG treatment. This result indicates that, in MNNGinduced necroptosis, BAX is not directly processed by calpains.

BID, but not BIM or BAD, is necessary for MNNGinduced $\mathbf{B A X}$ activation. The negative results represented in Figure 2c led us to analyze other possibilities for calpainmediated BAX activation. Two manuscripts have already described that calpains control JNK1 activation ${ }^{20}$ and that AIF is released from mitochondria by JNK1-mediated activation. ${ }^{7}$ Moreover, it has been demonstrated that JNK phosphorylation and activation of the $\mathrm{BH} 3-$ only proteins, BIM and $B A D$, couple the stress-activated signaling pathway to the BAX-dependent cell death machinery. ${ }^{21,22}$ Thus, a working hypothesis is that calpains activate JNK1 which, by means of BIM or BAD phosphorylation, yields active BAX. A third BH3-only protein, BID, could also be implicated in calpain-mediated BAX activation. Indeed, calpains cleave $\mathrm{BID}$ in a $15-\mathrm{kDa}$ fragment similar to the pro-apoptotic caspase-cleaved tBID. ${ }^{23}$ Once generated, tBID could provoke mitochondrial AIF release. ${ }^{13,24,25}$ Thus, a second $\mathrm{BH} 3-o n l y$ working hypothesis is that calpains cleave BID into tBID. Truncated BID could then regulate BAX activation, which provokes mitochondrial tAIF release and necroptosis.

We assessed the potential role of the $\mathrm{BH} 3$-only proteins BIM, BAD, and BID in MNNG-induced PCD by means of gene knockout MEFs. When comparing with WT, we observed that in $B I M^{-1-}$ or $B A D^{-/-}$cells, both MNNG-induced necroptosis and $B A X$ activation remained unaffected. In contrast, MNNGinduced BAX activation and death were efficiently delayed in $B I D^{-1-}$ MEFs (Figures $\left.3 a-c\right)$. In these cells, the percentage of PS exposure and loss of viability reached $\sim 10 \% 9 \mathrm{~h}$ after MNNG treatment. At the same time, MNNG-induced death in about $60 \%$ of WT cells. As expected from the absence of BAX activation in $B I D^{-/-}$MEFs (Figure 3c), the presence of tAIF in extramitochondrial compartments was negative (Figure $3 d$ ). As internal control, we confirmed that WT, $B I M^{-1-}, B A D^{-/-}$, and $B I D^{-1-}$ cells treated with the caspase-dependent apoptosis inducer STS displayed similar cell death levels (Figure 3a), confirming that these MEFs remained sensitive to other PCD inducers. In any case, BID and not BIM or BAD deficiency disabled BAX activation and necroptosis.

By reintroducing BID-wt cDNA into $B I D^{-/-}$cells by lentiviral transduction, we corroborated that the loss of the BAXdependent necroptotic hallmarks was due to the specific lack of BID. Indeed, BID-wt CDNA transduction fully resensitized $B I D^{-/}$cells to MNNG-mediated PCD, including mitochondrial damage, BAX activation, TUNEL positivity, and cell-viability loss (Figures 4a-d). 
a

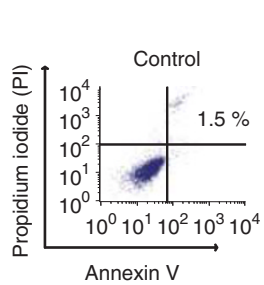

c

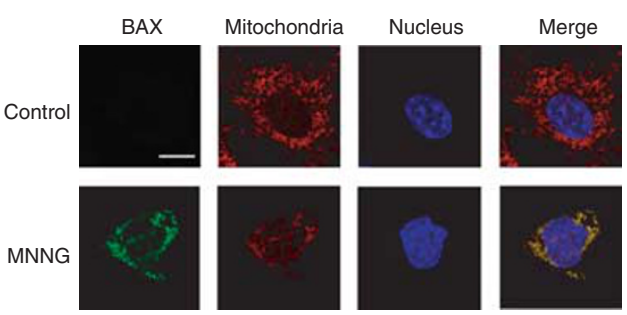

MNNG $(9 \mathrm{~h})$

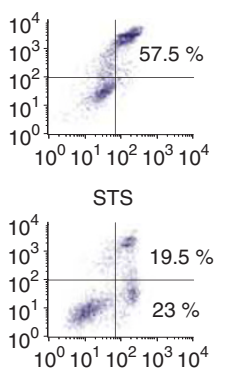

MNNG (9 h) + QVD

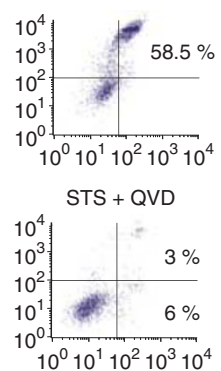

b
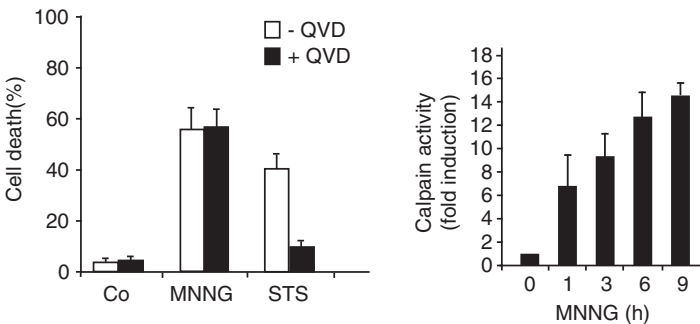

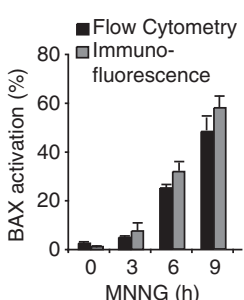

d

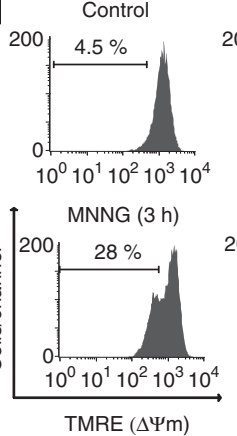

MNNG $(6 \mathrm{~h})$
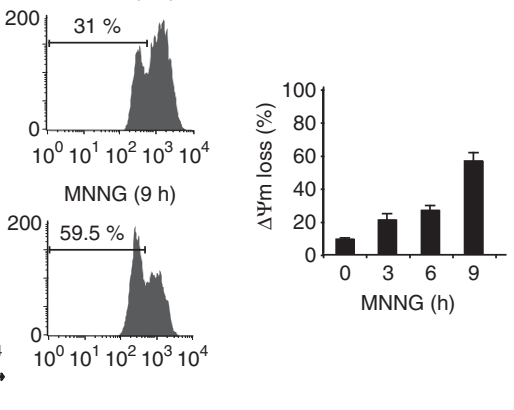

e

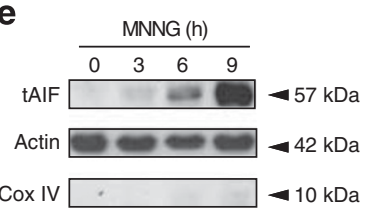

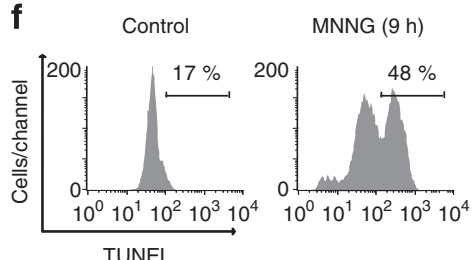

Figure 1 MNNG-induced caspase-independent necroptosis. (a) After the indicated time post MNNG or STS treatment, WT MEFs were stained with Annexin V and PI, and the frequency of Annexin V and PI-positive labeling (\% cell death) was recorded by flow cytometry and illustrated as a plot. Data are the means of six independent experiments \pm S.D. Representative cytofluorometric plots are shown. Percentages in MNNG-treated cells refer to double-positive staining, and in STS-treated cells to Annexin V and PI-positive labeling. When indicated, WT MEFs were pre-incubated $(1 \mathrm{~h})$ with the pan-caspase inhibitor QVD before induction of cell death. Note that QVD inhibits STS-induced caspase-dependent apoptosis but not MNNG-mediated caspase-independent necroptosis. (b) Fluorometric analysis of calpain activity observed in cytosolic extracts obtained from WT treated with MNNG for the indicated times. One unit refers to basal calpain activity observed in untreated WT cells. Data are the means of five independent experiments \pm S.E.M. (c) Immunofluorescent staining of activated BAX detected in WT MEFs untreated (control) or treated with MNNG (6 h). To visualize mitochondria, cells were incubated with Mitotracker Red before fixation. Hoechst 33342 was used to stain DNA. A representative overlay of activated BAX, Mitotracker Red and Hoechst 33342 nuclear staining is shown. The number of cells presenting activated BAX were quantified and plotted as a percentage of total cells. Data are the means \pm S.D. $(n=5)$. Bar: $10 \mu \mathrm{m}$. Alternatively, MEFs were treated with MNNG for the indicated times, and BAX activation was measured by flow cytometry and illustrated as a bar chart. Data are the means \pm S.D. $(n=5)$. (d) Cells were treated with MNNG for the indicated time, then labeled with TMRE and assessed for $\Delta \Psi \mathrm{m}$ by flow cytometry. Results are the means of six independent experiments \pm S.D. In cytometry panels, percentages refer to cells with $\Delta \Psi \mathrm{m}$ loss. TMRE, tetramethylrhodamine ethyl ester. (e) Cytosolic fractions, recovered after MNNG treatment, were blotted for tAIF detection. MNNG treatment induces time-dependent tAIF release to cytosol. Actin (cytosolic marker) and Cox IV (mitochondrial marker) were used to control protein loading and fractionation quality. (f) At the indicated times after MNNG treatment, WT MEFs were stained for the detection of $3^{\prime}-\mathrm{OH}$ DNA breaks and analyzed by flow cytometry. Data are the means of five independent experiments \pm S.D. In representative cytofluorometric plots, percentages refer to TUNEL-positive cells

The BAX-dependent necroptotic hallmarks are abolished in MNNG-treated $B I D^{-1-}$ MEFs. To gain insights into the role of BID in the MNNG-mediated PCD pathway, we next determined whether the absence of BID exclusively affected BAX activation or if, on the contrary, BID deficiency disabled other key necroptotic events. We first verified whether PARP-1 and calpains, which act upstream of BAX in MNNG-mediated PCD, were activated or not in $B I D^{-/}$MEFs. PARP-1 activation is assessed by the inverse relationship existing between poly(ADP-ribose) (PAR) and $\mathrm{NAD}^{+}$and ATP cellular levels. Note that we have previously demonstrated that the specific activation of PARP-1 in MNNG-mediated necroptosis is responsible for both the synthesis of the PAR polymers observed and the depletion of $\mathrm{NAD}^{+}$and ATP cellular pools. ${ }^{8}$ As shown by the formation of PAR polymers, PARP-1 was equally activated in WT and $B I D^{-/-}$MEFs (Figures $5 a$ and $b$ ). This demonstrated that, even in the absence of BID, PARP-1 is an active enzyme. In line with that, MNNG caused a rapid and similar decrease in $\mathrm{NAD}^{+}$and ATP cellular levels in both WT and $B I D^{-1-}$ MEFs (Figures $5 c$ and $d$ ). The specificity of the PARP-1 dependent $\mathrm{NAD}^{+}$loss associated with MNNG treatment in these cells was confirmed using a pharmacological PARP inhibitor, PJ34. Meanwhile, calpain activity was measured with the help of a cell-permeable substrate that reports calpain activity in live cells. This approach showed that MNNG 

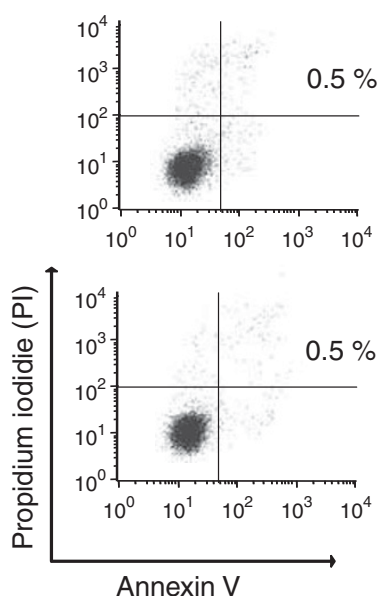

b

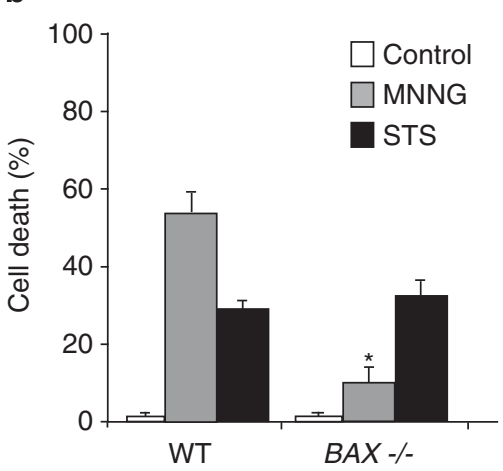

MNNG (9 h)
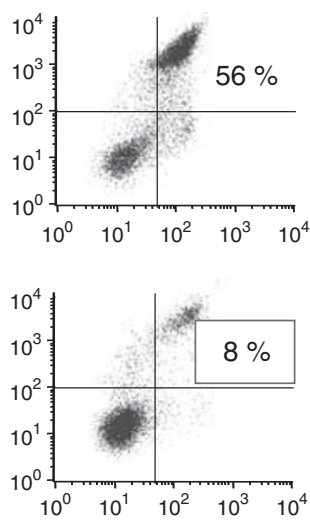

STS
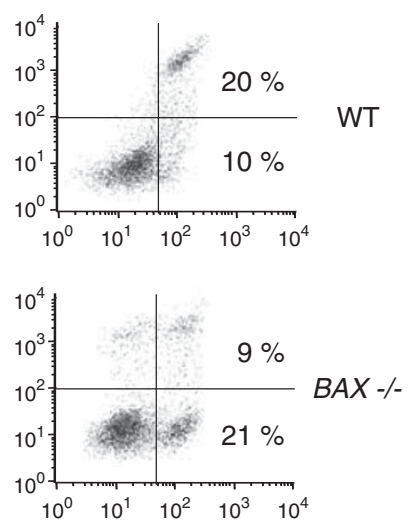

c

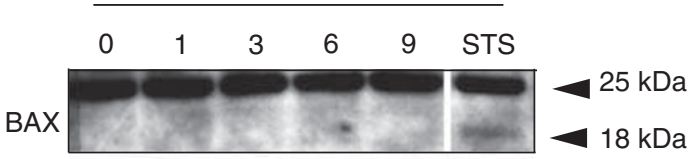

Figure 2 The activation of BAX is a key step in necroptosis. (a) WT and BAX ${ }^{-1-}$ MEFs were untreated (control) or treated with MNNG (9h) or STS, labeled with Annexin V and PI, and analyzed by flow cytometry. Representative plots are shown. Percentages in MNNG-treated cells refer to double-positive staining, and in STS-treated cells to Annexin V and PI-positive labeling. The square highlights the absence of cell-viability loss recorded in $B A X^{-1-}$ MEFs after MNNG treatment. (b) Cells were stained as in $\mathbf{a}$, and the frequency of Annexin V and PI-positive labeling (\% cell death) was recorded and expressed as a plot. Data are the means of five independent experiments \pm S.D. ${ }^{*} P<0.05$. (c) BAX immunoblotting detection in total extracts from WT MEFs untreated or treated with MNNG at different times. STS-treated cells were used as a positive control. The membrane was stained with naphtol blue (NB) to assess protein loading

induced rapid calpain activation in WT and $B I D^{-1-}$ MEFs (Figure 5e). Overall, these results indicate that $B I D^{-/-}$ MNNG-treated MEFs activate PARP-1 and calpains in exactly the same way as WT cells. In contrast, MNNGtreated $B I D^{-1-}$ MEFs never present BAX-dependent necroptotic hallmarks: $\Delta \Psi \mathrm{m}$ drop, tAIF release, and TUNEL positivity (Figures $5 \mathrm{f}-\mathrm{h}$ ).

These data raised an additional question: How can MNNGtreated $B I D^{-/-}$MEFs be viable with activated PARP-1/ calpains, consumed NAD ${ }^{+}$/ATP pools, and massive DNA damage (assessed by a COMET assay, Supplementary Figure 2A)? To answer this question, we performed longterm experiments in MNNG-treated WT and $B I D^{-1-}$ MEFs. As depicted in Supplementary Figure $2 \mathrm{~b}$, at $12 \mathrm{~h}$ post MNNG treatment, $98 \%$ of WT MEFs were necroptotic. In contrast, only $\sim 20 \%$ of $B I D^{-/-}$cells exposed the characteristic double Annexin V/PI-positive labeling. Strikingly, a significant population of $B I D^{-1-}$ MEFs ( $45 / 50 \%$ ) remained viable even $24 \mathrm{~h}$ post MNNG incubation (Supplementary Figures $2 B$ and $C$ ). The rest of the $B I D^{-1-}$ population exploded (Supplementary Figure 2D). Overtime, similarly to what has been previously reported for MNNG-treated $H 2 A X^{-/-}$MEFs, ${ }^{14}$ it seems that the cell is unable to achieve the necroptotic PCD program in the absence of BID. As a result, the 'highly damaged' cell, which is unable to proliferate/divide (Supplementary Figure 3), explodes by an uncontrolled form of necrosis.

Altogether, our results identify BID as a key component of MNNG-induced necroptosis. By controlling BAX activation, BID manages this type of PCD.

MNNG-induced DNA damage and necroptosis is not influenced by the pro-survival function of BID. BID is not only a pivotal executioner of PCD. In response to a DNA double-strand breaks (DSB) damage such as that triggered by etoposide, BID activates a pro-survival cell cycle regulatory activity mediated by its phosphorylation at Ser61 and 78 (S61 and S78). ${ }^{26,27}$ Thus, to achieve the characterization of the role of BID in MNNG-induced DNA damage, which also provokes DSB in DNA, ${ }^{14}$ we evaluated the relevance of the pro-survival role of BID. Specific immunoblotting detection successfully revealed a timedependent BID phosphorylation in MNNG-treated cells (Supplementary Figure $3 \mathrm{~A}$ ), suggesting that the prosurvival role of BID was enabled. We explored this 
a
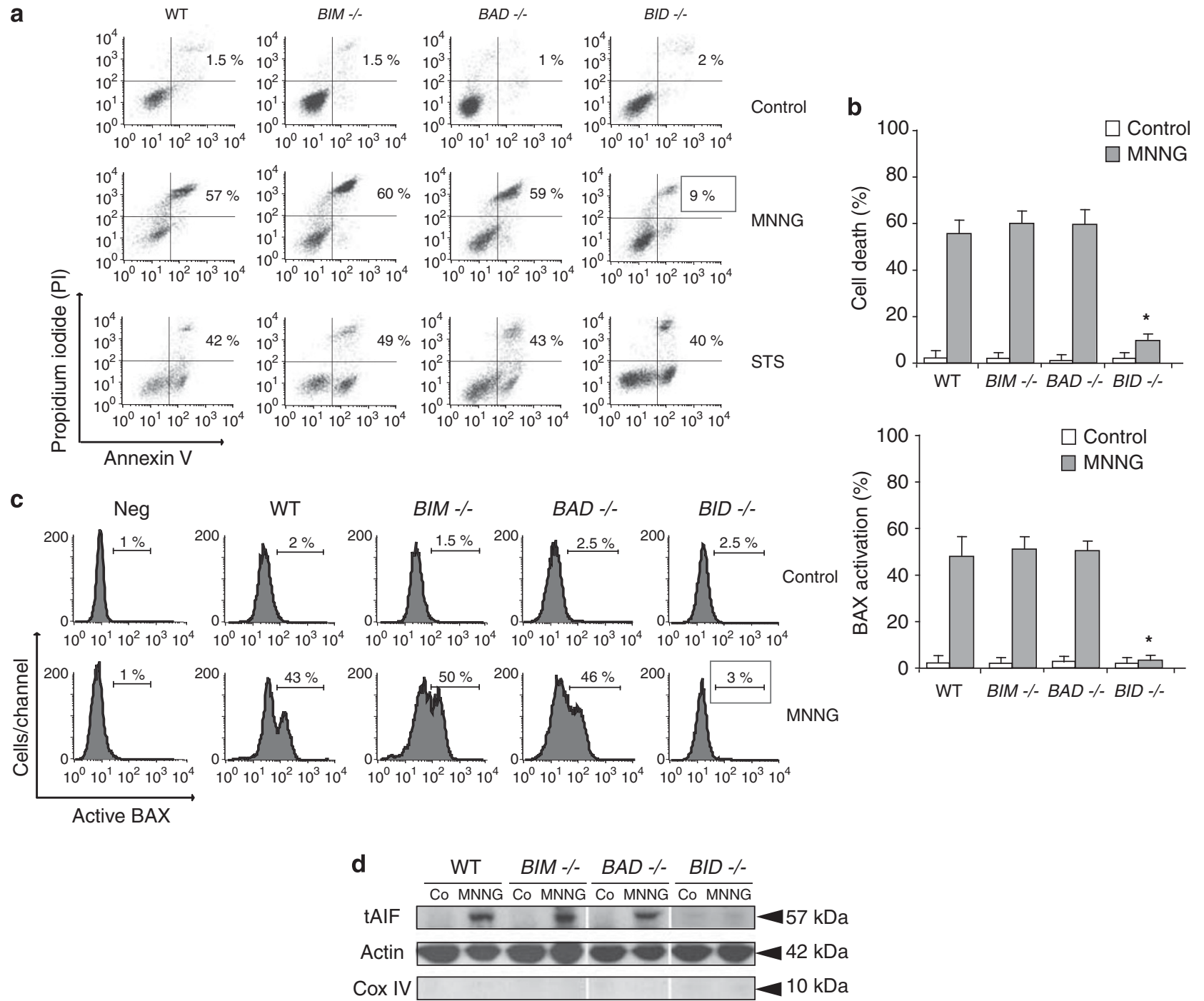

Figure 3 BID but not BIM or BAD deficiency disabled BAX activation and MNNG-induced necroptosis. (a) WT, BIM ${ }^{-/-}, B A D^{-/-}$, and $B I D^{-1-}$ MEFs were untreated (control) or treated with MNNG $(9 \mathrm{~h})$ or STS, labeled with Annexin V and PI, and analyzed by flow cytometry. Representative cytofluorometric plots are shown. The percentages refer to the frequencies of Annexin $\mathrm{V}$ and PI positive staining. (b) WT, $B I M^{-1-}, B A D^{-1-}$, and $B I D^{-1-}$ MEFs were untreated (control) or treated with MNNG (9h), stained as in a, and the frequency of double-positive labeling was recorded and expressed as a percentage. Data are the mean \pm S.E.M. $(n=5)$. ${ }^{*} P<0.05$. (c) WT, BIM ${ }^{\prime-}$, $B A D^{-/-}$, and $B I D^{-1-}$ MEFs were treated with MNNG, and BAX activation was recorded by flow cytometry with the help of an $\alpha$-Bax antibody (clone $6 A 7$ ) specifically designed against the active conformation of BAX. Data in bar chart are the means of six independent experiments \pm S.D. ${ }^{*} P<0.05$. Representative cytofluorometric plots of untreated (control) and MNNG-treated $(9 \mathrm{~h})$ cells are shown. Percentages correspond to cells with active BAX. Note that, in the absence of $\alpha$-Bax antibody, the labeling with the secondary antibody (Neg. in cytofluorometric plots) yields negative results. The squares in a and $\mathbf{c}$ highlight the absence of cell-viability loss and BAX activation recorded in $B I D^{-1-}$ MEFs after MNNG treatment. Neg, negative. (d) Cytosolic fractions recovered from WT, $B I M^{-1-}, B A D^{-/-}$, and $B I D^{-1-}$ MEFs untreated (Co) or treated with MNNG $(9 \mathrm{~h})$ were probed for tAIF detection. Actin was used to control protein loading

possibility by a cell cycle analysis performed in MNNGtreated WT and $B I D^{-/-}$cells. Surprisingly, contrary to what had been previously reported for etoposide, ${ }^{26}$ the percentages of the different cell cycle phases remained similar before and after MNNG treatment in both cell types (Supplementary Figures 3B, C and 4). This result opens two possibilities: (i) MNNG treatment causes the arrest of the cell cycle or (ii) this alkylating agent does not alter the cellular cycling at all. We verified these two alternatives by a BrdU/PI assessment. As revealed by the absence of proliferating cells, treatment with MNNG provoked the cell cycle halt in both WT and $B I D^{-/}$MEFs (Supplementary Figure 3D). Altogether, our results differentiate the response of $B I D^{-/-}$ cells to MNNG and etoposide, and suggest that necroptosis is not modulated by the cell cycle/DNA repair mechanisms implicating phosphorylated BID. This is substantiated by a flow cytometry assessment performed in $B I D^{-/}$MEFs stably transfected with BID-wt or a non-phosphorylatable BIDS61A/S78A cDNA (Ser61 and 78 of BID-wt were mutated to Ala). Our data show that, contrary to what has been reported after etoposide DSB generation, MNNG does not induce a different rate of necroptosis in $B I D^{-/}$cells expressing BIDS61A/S78A or BID ${ }^{-1-}$ cells expressing BID-wt (Supplementary Figure $3 \mathrm{E}$ ). Therefore, we conclude that the phosphorylation of BID does not regulate the response of MEFs to the DNA damage provoked by MNNG. This 


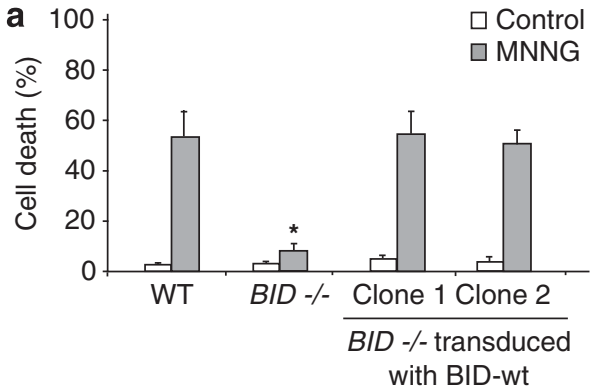

C

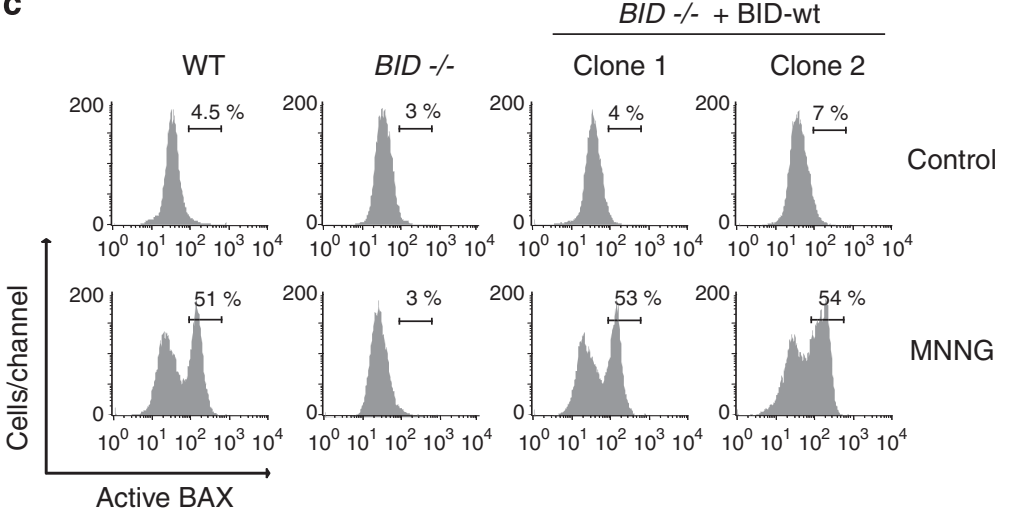

d

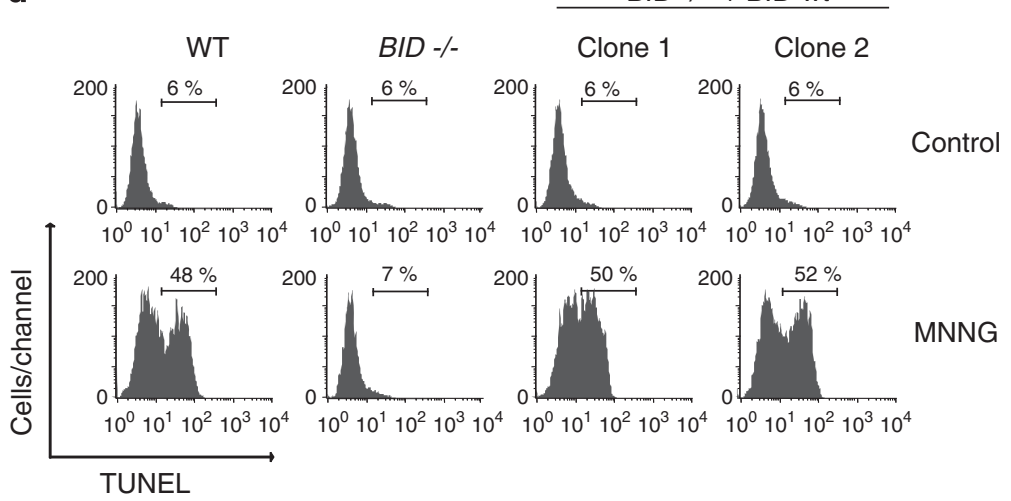

b

+ BID-wt
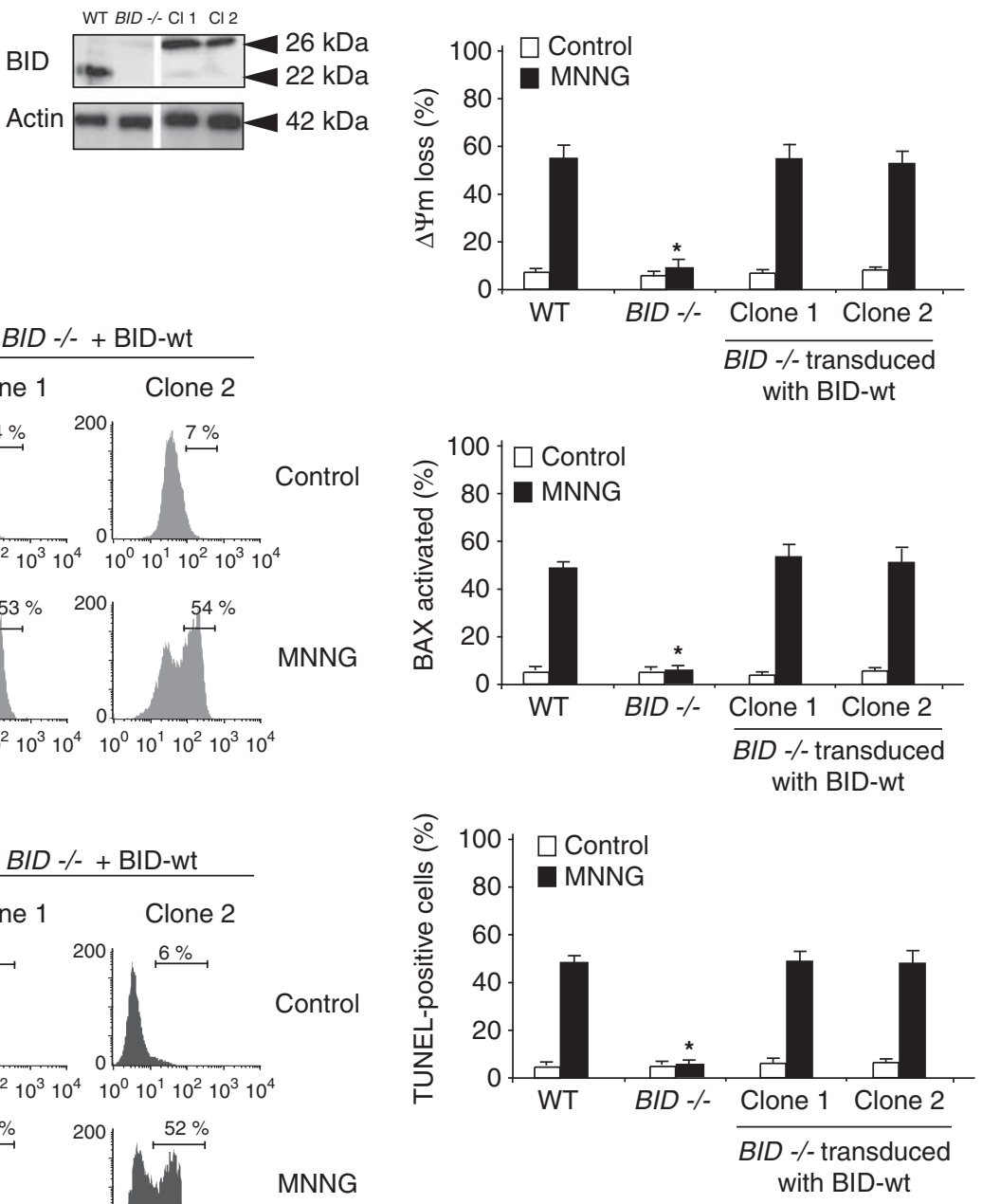

Figure 4 Lentiviral transduction of $B I D^{-/-}$MEFs with V5-tagged BID-wt CDNA restores BAX activation and MNNG-induced necroptosis. (a) WT, BID ${ }^{-/}$, and two selected clones of $B I D^{-/-}$MEFs cells expressing BID-wt were untreated (control) or treated with MNNG $(9 \mathrm{~h})$, and labeled with Annexin V and PI. The frequency of doublepositive labeling was recorded and expressed as a plot. Data are the mean \pm S.D. $(n=4) .{ }^{*} P<0.05$. The expression level of BID in these cells was assessed by immunoblotting. Note the different apparent molecular mass of endogenous BID ( $\sim 22 \mathrm{kDa})$ and lentiviral-transduced BID-V5 ( $\sim 26 \mathrm{KDa})$. Actin was used to control protein loading. (b) MEFs treated as in a were labeled with TMRE, and assessed for $\Delta \Psi \mathrm{m}$ by flow cytometry. The frequency of cells with $\Delta \Psi \mathrm{m}$ loss was recorded and expressed as a plot. Data are the means of four independent experiments \pm S.D. ${ }^{*} P<0.05$. (c) The panel of MEFs used in a was untreated (control) or MNNG-treated ( $9 \mathrm{~h}$ ), and BAX activation was measured by flow cytometry and illustrated as a bar chart. Data are the means of four independent experiments \pm S.D. In representative cytofluorometric plots, percentages correspond to cells with active BAX. TMRE, tetramethylrhodamine ethyl ester. (d) MEFs were untreated (control) or MNNG-treated ( $9 \mathrm{~h}$ ), and the presence of $3^{\prime}-\mathrm{OH}$ DNA breaks was assessed by flow cytometry and illustrated as a plot. Data are the means of four independent experiments \pm S.D. In cytofluorometric plots, percentages correspond to TUNEL-positive cells

necroptosis is exclusively modulated by the apoptogenic function of BID.

BID is cleaved into tBID by calpains in MNNG-mediated necroptosis. As indicated above, the pro-apoptotic properties of the $\mathrm{BH} 3$-only protein, BID, are pivotal in the BAX activation that controls caspase-independent necroptosis. In apoptotic caspase-dependent PCD, this apoptogenic action is generally arbitrated by the caspasecleaved BID, tBID. ${ }^{28,29}$ In apoptotic PCD, tBID has a double role in BAX activation. On the one hand, tBID opens the $\mathrm{N}$-terminal moiety of $\mathrm{BAX} .{ }^{30}$ On the other hand, tBID redistributes to mitochondria where it favors $B A X$ recruitment and activation. ${ }^{16,31,32}$ Hence, it seems mandatory to verify whether, in MNNG-treated MEFs, BID exerts its BAX activation function by means of the truncated form. As indicated in Figure $6 \mathrm{a}$, a kinetic immunoblot analysis performed with a specific antibody demonstrated that a fraction of BID became cleaved into tBID after MNNG treatment. The time-dependent tBID generation correlated 
a

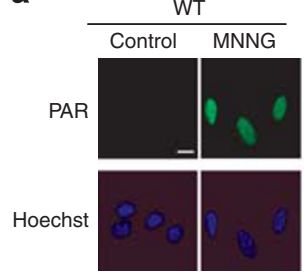

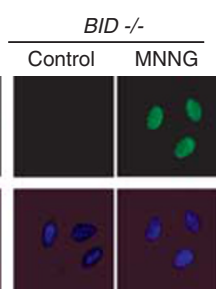

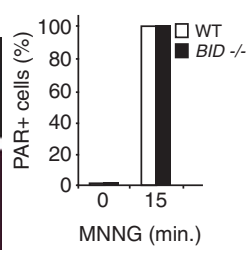

b

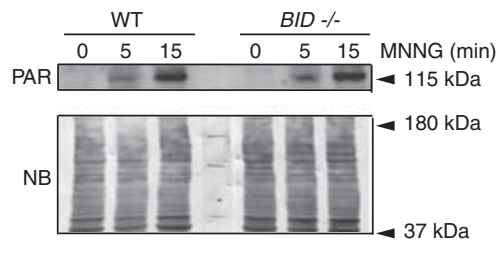

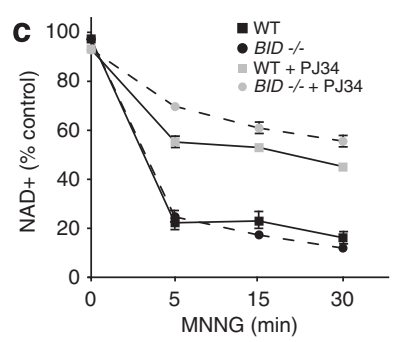

d

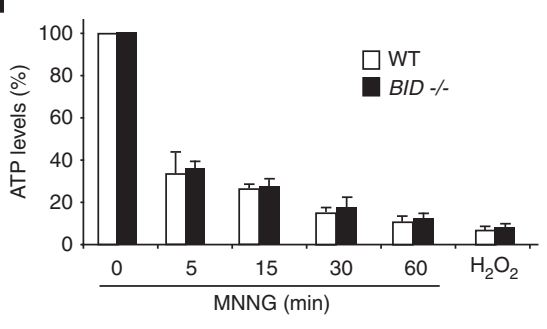

f

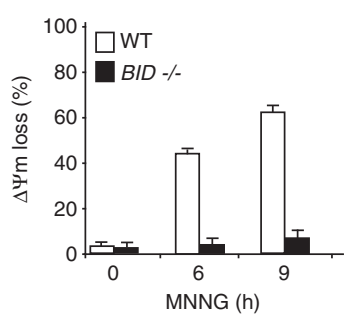

g

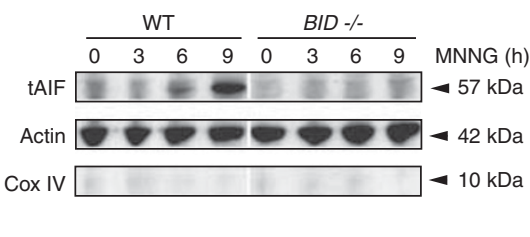

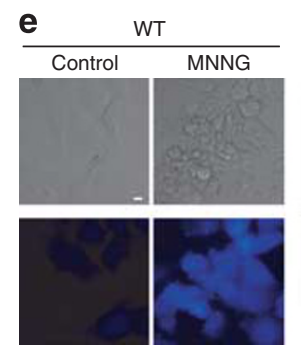
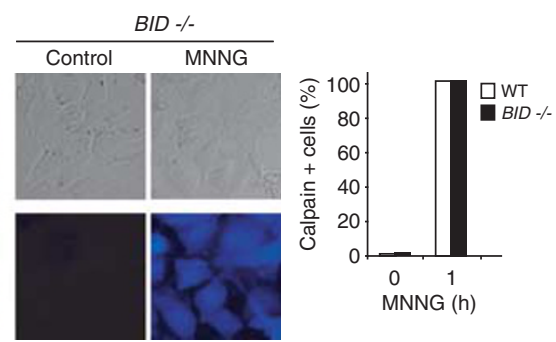

h

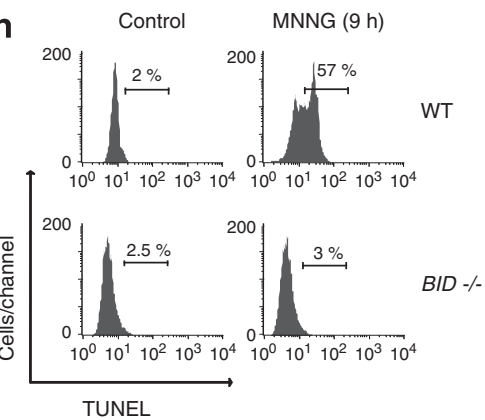

Figure 5 BID acts downstream of PARP-1 and calpains but upstream of BAX activation, mitochondrial damage, tAIF release, and DNA degradation in MNNG-induced PCD. (a) WT and BID ${ }^{-1-}$ MEFs were untreated (control) or treated with MNNG (15 min), immunostained for PAR detection (green), and visualized by fluorescent microscopy. Hoechst 33342 (blue) was used to visualize the nuclei. Representative micrographs of each cell type are shown. Bar: $10 \mu \mathrm{m}$. After MNNG treatment, the entire WT and BID ${ }^{-1-}$ cell population (100\% of cells) display PAR-positive labeling. This experiment was repeated six times, yielding similar results (the entire WT and BID ${ }^{-1}$ cell population display PAR-positive labeling). (b) PAR immunoblotting detection in lysates from WT and $B I D^{-1-}$ MEFs untreated or treated with MNNG at different times. The membrane was stained with naphtol blue (NB) to assess protein loading. (c) WT and BID ${ }^{-1-}$ MEFs were treated with MNNG at the times indicated, and analyzed by measuring absorbance at $570 \mathrm{~nm}$ to assess total NAD ${ }^{+}$ levels. Concentrations of $\mathrm{NAD}^{+}$were normalized to those from untreated cells. Results are the means of five independent experiments \pm S.E.M. A pharmacological PARP inhibitor, PJ34, helped to determine the specificity of the PARP-dependent NAD ${ }^{+}$loss associated with MNNG treatment. (d) Quantification of the intracellular ATP levels in WT and BID ${ }^{-\prime}$ MEFs treated with MNNG at different times. $\mathrm{H}_{2} \mathrm{O}_{2}$ was used as a positive control. A value of $100 \%$ refers to the basal level of ATP scored in untreated cells. Data are the means of five independent experiments \pm S.E.M. (e) Fluorescent assessment of calpain activity measured in WT and BID ${ }^{-1}$ MEFs untreated (control) or treated with MNNG (1 h). Phase-contrast was used to visualize cells. Representative micrographs of each treatment are shown. After MNNG treatment both WT and BID ${ }^{-1}$ MEFs (100\%) display calpain-positive staining. This experiment was repeated four times, yielding similar results. Bar: $10 \mu \mathrm{m}$. (f) WT and $B I D^{-/-}$MEFs were treated with MNNG for the indicated times, then labeled with TMRE and assessed for $\Delta \Psi \mathrm{m}$ by flow cytometry. Results refer to cells with $\Delta \Psi \mathrm{m}$ loss and are the means of six independent experiments \pm S.E.M. TMRE, tetramethylrhodamine ethyl ester. (g) Cytosolic fractions recovered from WT and $B I D^{-/-}$MEFs after MNNG treatment at different times were probed for tAIF detection. Actin was used to assess protein loading. (h) WT and $B I D^{-/-}$MEFs were untreated or treated with MNNG $(9 \mathrm{~h})$, stained for the detection of $3^{\prime}-\mathrm{OH}$ DNA breaks, and analyzed by flow cytometry. Percentages refer to TUNEL-positive cells. This experiment was repeated ten times, with low experimental variability

to MNNG-induced necroptosis (Figure 1a). Moreover, as was to be expected, tBID localized in mitochondria, where it was able to achieve its BAX-activating function (Figure 6a, right panels).

How does BID become activated/cleaved in caspaseindependent necroptosis? Are calpains implicated in this cleavage? To answer these questions, we first tested whether BID was cleaved in calpain-inactivated knockout MEFs $\left(\mathrm{CAPN}^{-1-}\right) .{ }^{20}$ As depicted in Figure 6b, MNNG-induced BID cleavage was abolished in $C A P N 4^{-1-}$ cells. Note that these cells treated with STS displayed similar levels of tBID to WT cells. This confirmed that BID could be caspase-dependent cleaved in $C A P N 4^{-/}$MEFs. Interestingly, as could be expected from the absence of tBID in MNNG-treated
CAPN4 ${ }^{-/-}$MEFs, BAX activation, $\triangle \Psi \mathrm{m}$ drop, PS exposure, and cell-viability loss were also negative (Figures $6 \mathrm{c}-\mathrm{e}$ ). These results place BID between calpains and BAX in this mode of death and indicate that calpains are implicated in the tBID generation associated to MNNG-mediated PCD.

Indeed, is BID directly cleaved into tBID by calpains or is tBID generated by a protease downstream of calpains? To fully analyze these two possibilities we assessed whether calpain non-cleavable (nc) BID restored MNNG-mediated necroptosis in $B I D^{-1-}$ MEFs. The reactivation of MNNGmediated necroptosis in these cells would indicate that a protease other than calpains generates the processed fragment of BID. The opposite result (calpain ncBID is not processed into tBID after MNNG treatment and is unable to 
a
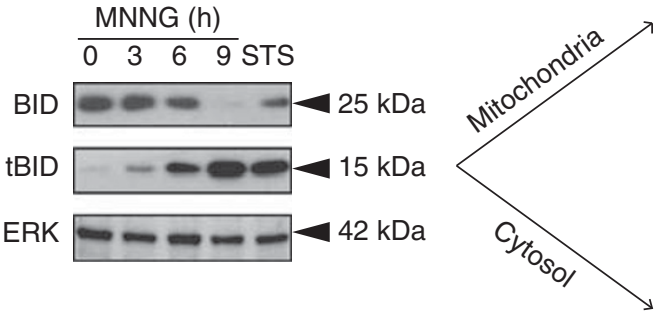

b

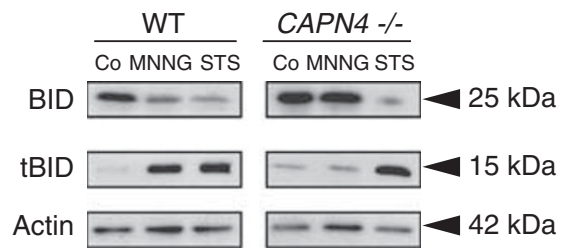

e
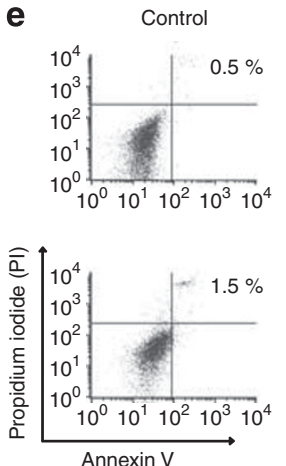
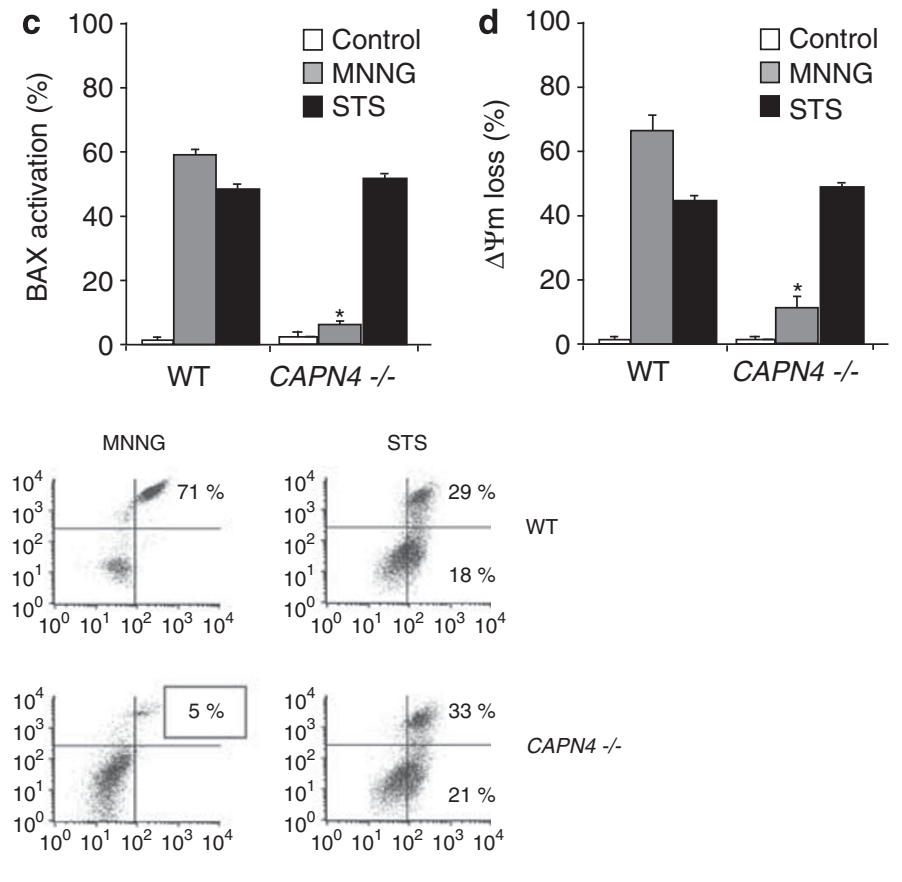

CAPN4 -/-

Figure $6 \quad B I D$ is cleaved into tBID via calpains and localizes in mitochondria during MNNG-induced necroptosis. (a) Lysates from MEFs treated by MNNG at the indicated times were prepared, and blotted for BID and tBID detection. STS-treated cells were used as a positive control. Alternatively, mitochondrial and cytosolic extracts of cells treated or not with MNNG at different times were analyzed by western blotting for the presence of tBID. STS-treated cells were used as a positive control. Cox IV (mitochondrial marker) and pan-ERK (cytosolic marker) were used to control fractionation quality and protein loading. This experiment was repeated three times, yielding comparable results. (b) BID and tBID immunoblotting detection in lysates from WT and CAPN4 ${ }^{-/-}$MEFs untreated (Co) or treated with MNNG (9h) or STS. The membrane was reblotted for actin detection to control protein loading. Note the absence of tBID in MNNG-treated CAPN4 ${ }^{-/-}$MEFs. (c) WT and CAPN4 ${ }^{-/-}$MEFs were treated with MNNG $(9 \mathrm{~h})$ or STS, and BAX activation was measured by flow cytometry and illustrated as a bar chart. Data are the means of four independent experiments \pm S.D. ${ }^{*} P<0.05$. (d) WT and $C A P N 4^{-1-}$ MEFs were treated or not with MNNG $(9 \mathrm{~h})$ or STS, then labeled with TMRE and assessed for $\triangle \Psi \mathrm{m}$ by flow cytometry. Results refer to cells with $\triangle \Psi \mathrm{m}$ loss \pm S.D. $(n=6)$. ${ }^{*} P<0.05$. TMRE, tetramethylrhodamine ethyl ester. (e) WT and CAPN4 ${ }^{-1-}$ cells were untreated (control) or treated with MNNG $(9 \mathrm{~h})$ or STS, labeled with Annexin $\mathrm{V}$ and PI, and analyzed by flow cytometry. Representative cytofluorometric plots are shown. Percentages in MNNG-treated cells refer to double-positive staining, and in STS-treated cells to Annexin V and PI-positive labeling. The square highlights the absence of cell-viability loss recorded in CAPN4 ${ }^{-1-}$ MEFs after MNNG treatment

restore $\mathrm{PCD}$ ) would indicate that BID is directly cleaved into tBID by calpains to promote BAX activation. To design the calpain ncBID vectors, we took into consideration theoretical sequential/structural determinants of calpainmediated cleavage ${ }^{33}$ and previous work suggesting that calpains processed BID into tBID at position Gly70. ${ }^{34}$ Thus, we generated two constructs: BID-G70A, which contains the Gly70 mutated to Ala, and BID- $\Delta 68-71$, in which the entire 'calpain-cleavable region of BID' has been deleted. Note that, similarly to the caspase-mediated BID cleavage occurring at D59 position, ${ }^{28}$ the cleavage at G70 provoked the removal of the BID N-terminus and exposed the amphipathic $\alpha$ helix BH3 on the active C-terminal tBID p15 fragment (Figure 7a). As illustrated in Figures $7 \mathrm{~b}-\mathrm{e}$ and Supplementary Figure 5, transduction of $B I D^{-/-}$MEFs with lentiviruses carrying vectors of BID-wt, a caspase ncBID-D59A mutant, ${ }^{35}$ or the two calpain ncBID mutants defined above revealed that: (i) BID-wt and BID-D59A resensitized $B I D^{-/-}$cells to 
a

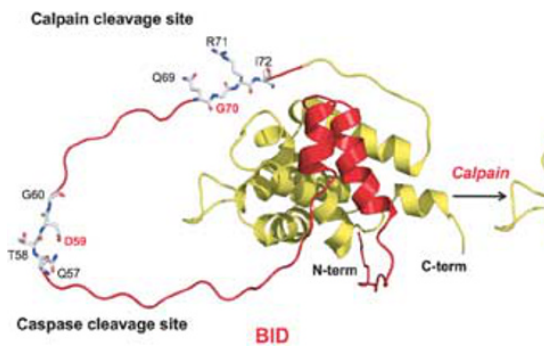

b

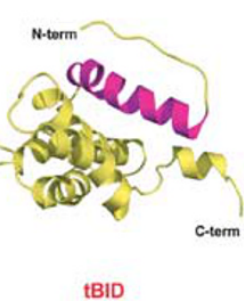

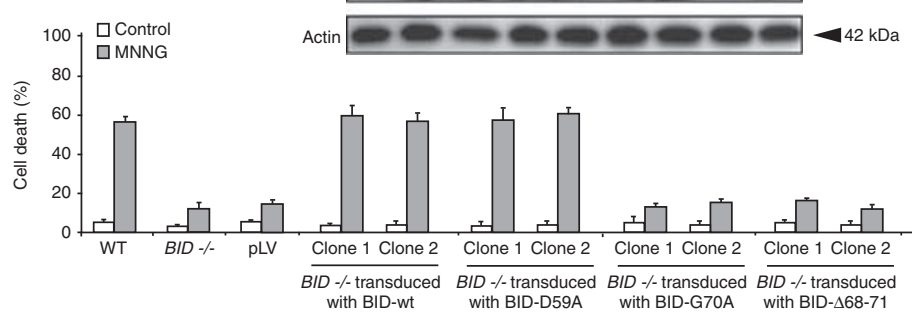

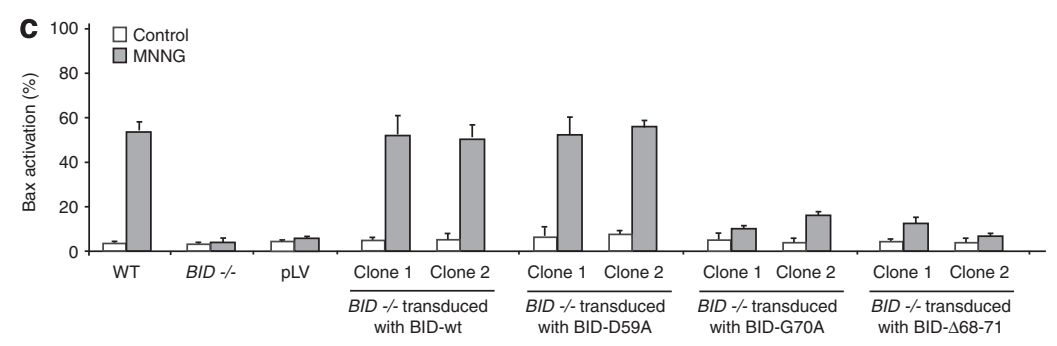

d

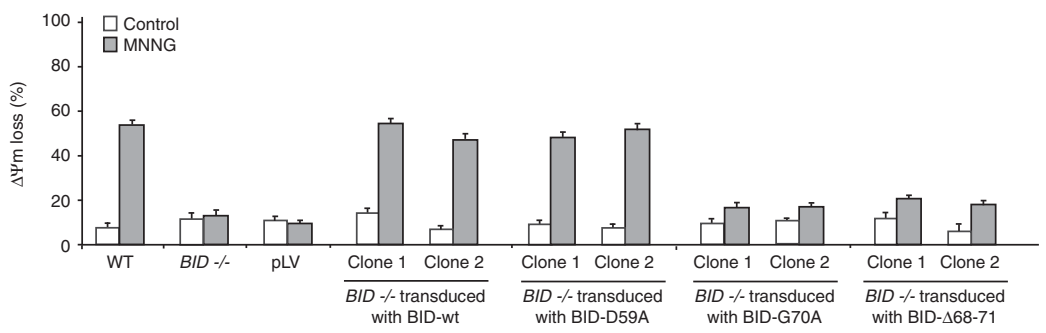

e

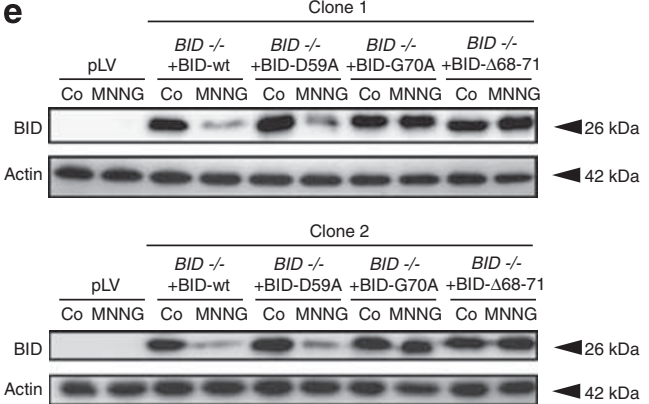

Figure 7 Calpains cleave BID into tBID at Gly70 in MNNG-induced necroptosis. (a) Ribbon structure of BID and tBID. Caspases and calpains cleave BID at the D59 and G70 amino-acidic position, respectively, to generate the truncated form of BID (tBID). This processing, which provokes the removal of a part of the BID N terminus (red), discloses the BH3 $\alpha$-helix (magenta) on tBID. Here, we represent the tBID generated by calpain processing at G70. (b) WT, BID ${ }^{-1-}, B I D^{-/-}$transduced with the pLVX-IRESZs-Green lentiviral empty vector (pLV), and two selected clones of BID ${ }^{-/-}$MEFs cells expressing: (i) BID-wt, (ii) a caspase ncBID-D59A mutant, or (iii) two calpain ncBID mutants (BID-G70A and BID- $\triangle 68-71$ ) were untreated (control) or treated with MNNG $(9 \mathrm{~h}$ ) and labeled with Annexin V and PI. The frequency of double-positive labeling was recorded and expressed as a plot. Data are the mean \pm S.D. $(n=4)$. The expression level of BID in these cells was assessed by immunoblotting with the help of a V5 monoclonal antibody. Actin was used to control protein loading. (c) MEFs were untreated (control) or MNNG-treated ( $9 \mathrm{~h}$ ), and BAX activation was measured by flow cytometry and illustrated as a graph. Data are the means of four independent experiments \pm S.D. In representative cytofluorometric plots, percentages correspond to cells with active BAX. (d) The panel of MEFs used in b was untreated (control) or MNNG-treated $(9 \mathrm{~h})$, labeled with TMRE and assessed for $\Delta \Psi \mathrm{m}$ by flow cytometry. The frequency of cells with $\Delta \Psi \mathrm{m}$ loss was recorded and expressed as a bar chart. Data are the means of four independent experiments \pm S.D. TMRE, tetramethylrhodamine ethyl ester. (e) MEFs left untreated or treated with MNNG $(9 \mathrm{~h})$ were subjected to immunoblot detection of BID with the help of a V5 monoclonal antibody. BID-wt and the caspase ncBID-D59A were processed after MNNG treatment ( $\sim 80 \%$ of BID is cleaved after MNNG treatment, see Materials and Methods section for quantification details). In contrast, the calpain ncBID mutants BID-G70A and BID-D68-71 remained as precursor proteins. Similar results were observed in two independent clones. Actin was used to control protein loading

MNNG-induced necroptosis. This confirmed our results showing that AIF-mediated necroptosis is a caspaseindependent mode of PCD promoted by BID; (ii) BID-G70A or BID- $\Delta 68-71$ transduction does not restore the MNNG ability to induce necroptosis in $\mathrm{BID}^{-/-}$MEFs; and (iii) as was to be expected, BID-wt and BID-D59A are processed after MNNG treatment. On the contrary, BID-G70A and BID- $\Delta 68-71$ remain as precursor proteins. Note that $B I D^{-/}$ cells transduced with calpain ncBID mutants retain the apoptotic function (Supplementary Figure 6). Altogether, these data reveal that, in AlF-mediated necroptosis, calpains cleave BID into tBID at Gly70. The mutation/deletion of the calpain cleavage site of BID is sufficient to prevent BID processing, BAX activation, mitochondrial damage, and cell-viability loss.

\section{Discussion}

The present work uncovers a milestone in understanding the molecular mechanisms that regulate the necroptotic pathway induced by MNNG: the pivotal role of the BH3-only protein, BID. Together with our previous results ${ }^{8,14}$ our present data provide a detailed sequence of events for DNA damage-mediated necroptosis: MNNG treatment induces a PARP-1 hyperactivity that leads to calpain activation. Calpains generate the cleaved form of BID (tBID), which redistributes from the cytosol to mitochondria, where it regulates BAX activation. Once activated, BAX provokes mitochondrial damage and tAIF mitochondrial release. tAIF relocalizes to the nucleus and, associated to $\gamma \mathrm{H} 2 \mathrm{AX}$ and CypA, induces chromatinolysis and cell-viability loss (Figure 8). 


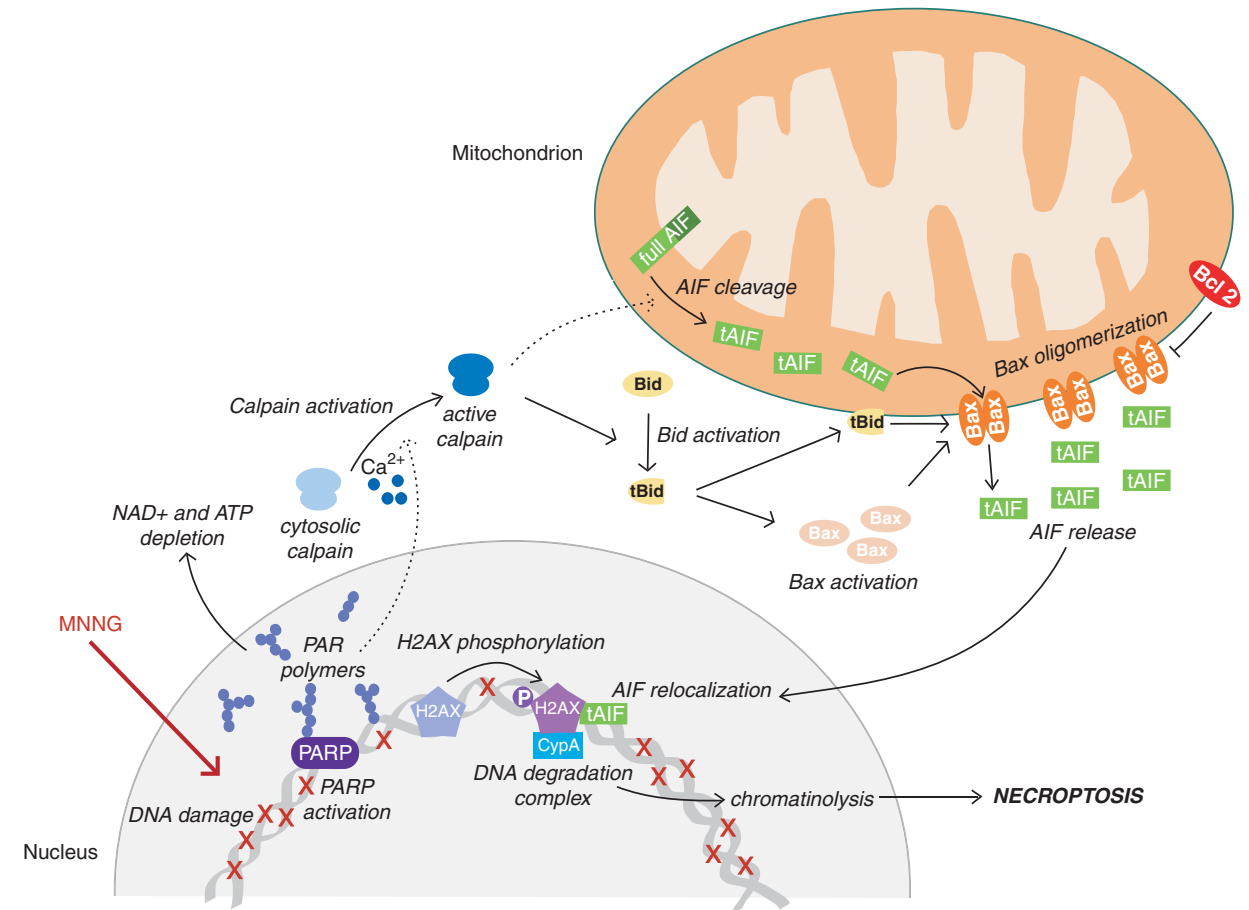

Figure 8 Representation of AIF-mediated necroptosis. MNNG-induced DNA damage leads through PARP-1 to NAD ${ }^{+}$, ATP depletion and calpain activation. Calpains cleave BID into tBID at Gly70. Once processed, tBID localizes in mitochondria, where it facilitates BAX activation. Furthermore, activated BAX provokes mitochondrial damage and favors the release of tAIF from mitochondria to the cytosol and nucleus. The anti-apoptotic protein BCL-2 can prevent this release. Upon transfer to the nucleus, tAIF associates with CypA and $\gamma \mathrm{H} 2 \mathrm{AX}$ to generate a DNA-degrading complex that promotes chromatinolysis and cell-viability loss

This work strengthens the idea that necroptosis is underpinned by a paradoxal PCD program, which is different from but similar to the broadly studied apoptotic program. It is different from apoptosis in as much as necroptosis substitutes caspases for calpains, enables a specific DNA-degrading module, and generates a controlled double Annexin V/PI labeling. ${ }^{18}$ It is similar to apoptosis because mitochondria has a pivotal role and operates under the control of typical apoptotic molecules (e.g., PARP-1, BID, BCL-2, BAX). The apoptotic and the necroptotic pathways therefore represent alternate outcomes of similar PCD programs.

When assessing how BAX could be activated in necroptosis induced by high doses of MNNG, we have focused on calpains. ${ }^{8}$ Ruling out the hypothesis of the direct activation of $B A X$ by calpain cleavage, and keeping in mind that BCL-2 and $B A X$ regulate MNNG-mediated $P C D$, we have examined the third subfamily of $\mathrm{BCL}-2$ proteins: the BH3-only subgroup. More precisely, our attention was directed to BAD, BIM and $B I D$, three BH3-only proteins that could be activated by calpains. In this sense, our data willingly demonstrate that $B A D$ and BIM are dispensable, whereas BID is essential to MNNG-induced necroptosis. More precisely, our data reveal that the $\mathrm{Ca}^{2+}$-dependent calpain Cys proteases control BAX activation via a cleavage of BID into tBID at Gly70. Notably, a single mutation in this amino acid is sufficient to preclude AlF-mediated necroptosis. This is an important finding that provides a major target in this PCD program. Additionally, calpain inhibitors and calcium chelators are now evinced as attractive tools in the regulation of the necroptotic pathway.

BID appears to link PARP-1 and calpains activity to BAX activation and tAIF-release in MNNG-mediated necroptosis.
This is a key issue because the presence of tAIF in the cytosol and further in the nucleus is essential to the generation of the DNA-degrading complex that manages necroptosis. ${ }^{14}$ These findings are in line with previous work on the relationships between BID and tAIF performed on purified mitochondria, on neuronal cell death induced by excitotoxic stimuli, oxidative stress, $\beta$-amyloid exposure, and on breast cancer cell death exposed to photodynamic therapy. ${ }^{13,24,25,36,37}$

As part of the molecular exploration of necroptosis, this work is indeed a first step in the analysis of the role of the BH3only protein, BID. Ensuing questions arise: could BID favor AIF mitochondrial release by altering the mitochondrial morphology, as in other apoptotic systems? ${ }^{25}$ Are MTCH2/ $\mathrm{MIMP}^{38}$ implicated in the mitochondrial recruitment of tBID in necroptosis? Future steps in the study of this $\mathrm{BH}$-only protein in necroptosis will unravel the mechanisms that control BIDmediated BAX activation and AIF-release, and will evaluate whether these mechanisms are similar in caspase-dependent and caspase-independent PCD.

Together with BID, two other BH3-only proteins have already been related to cell death programs with necrotic morphology: BMF and BNIP3. ${ }^{39,40}$ Their existence brings new perspectives to the development of small molecules mimicking the activity of $\mathrm{BH} 3-$ only proteins. Compounds such as Gossypol, ABT-263 or GX15-070 have been designed to overcome the overexpression of anti-apoptotic proteins in cancer cells. If these BH3-mimetics can also target necroptotic pathways, such drugs could find wider applications than initially expected. In this sense, the implication of necroptosis is described in brain ischemia, myocardial infarction, neurodegenerative diseases, head trauma, therapeutic killing of tumor 
cells, and so on. ${ }^{5,6}$ Thus, by shedding new light on the mechanisms regulating necroptosis, our new findings pave the way for novel pharmacological strategies that could target aberrant PCD. Furthermore, our work introduces the concept that, as in classical apoptosis, the entire BCL-2 family of proteins is at the crossroads of the necroptotic pathways.

\section{Materials and Methods}

Cell culture and cell death induction and inhibition. MEFs were cultured in DMEM supplemented with $10 \% \mathrm{FCS}, 2 \mathrm{mM}$ L-glutamine, and $100 \mathrm{U} / \mathrm{ml}$ penicillin/streptomycin (Invitrogen, Carlsbad, CA, USA), and maintained at $37^{\circ} \mathrm{C}$ in a $5 \% \mathrm{CO}_{2}$ atmosphere. $B A X^{-1-}$ MEFs were provided by SJ Korsmeyer (DanaFarber Cancer Institute, USA), $B M^{-1-}$ by DC Huang (Walter and Eliza Hall Institute, Australia), $B A D^{-/-}$by NN Danial (Harvard Medical School, USA), CAPN4 ${ }^{-1-}$ by PA Greer (Queen's University, Canada), and $R I P 1^{-/-}$by MA Kelliher (UMass Medical School, USA). BID ${ }^{-1}, B I D^{-/-}$MEFs stably transfected with BID-wt or a non-phosphorylatable BID-S61A/S78A were previously described ${ }^{26} B A X^{-1-}$, $B I M^{-/-}, B A D^{-/-}, B I D^{-/-}$, and $R I P 1^{-/-}$MEFs are derived from $C 57 \mathrm{BL} / 6$ mice and CAPN4 ${ }^{-/-}$from 129SvJ mice. $B A X^{-/-}, B I M^{-/}, B A D^{-/-}$, and $B I D^{-/-}$are SV40

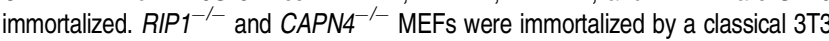
dilution method. WT cells from each lineage were used as a control.

To induce death, cells were treated with MNNG $(500 \mu \mathrm{M}, \mathrm{ABCR}$ GmbH, Karlsruhe, Germany) for $20 \mathrm{~min}$. The treating medium was replaced after incubation by a fresh medium devoid of MNNG, and cells ( $80 \%$ confluence) were cultured at the indicated times. As a control of caspase-dependent apoptosis, cells were incubated $6 \mathrm{~h}$ with STS $(1 \mu \mathrm{M})$ or etoposide $(20 \mu \mathrm{M})$ or $9 \mathrm{~h}$ with $\mathrm{TNF} / \mathrm{CHX}(50 \mathrm{ng} / \mathrm{ml} / 1 \mu \mathrm{g} / \mathrm{ml})$. In some experiments, cells were pre-incubated for $1 \mathrm{~h}$ with $\mathrm{Q}-\mathrm{VD} . \mathrm{OPh}$ (QVD, $10 \mu \mathrm{M}, \mathrm{MP}$ Biomedicals, Illkirch, France) or necrostatin-1 $(10 \mu \mathrm{M})$ before treatment.

Vectors and lentiviral transduction. Murine BID-wt, BID-D59A, BIDG70A, and BID- $\triangle 68-71$ cDNAs tagged with a V5 epitope were cloned into the pLVX-IRES-Zs-Green lentiviral vector (Clontech, Ozyme, St. Quentin en Yvelines, France). Viruses were produced into $293 \mathrm{~T}$ cells by $\mathrm{CaCl}_{2}$ transient transfection of the lentiviral constructs, and the packaging plasmids pMD2.G and psPAX-2 (Addgene plasmids 12259 and 12260, respectively). $48 \mathrm{~h}$ after transfection, lentiviral supernatants were harvested, clarified by filtration, and used immediately for $B I D^{-/-}$MEFs transduction with $4 \mu \mathrm{g} / \mathrm{ml}$ of polybrene. A total of $72 \mathrm{~h}$ after transduction, cells were diluted for immunoblot selection of individual clones. Clones with similar BID levels to WT BID MEFs were selected, expanded, and analyzed.

Flow cytometry. We used Annexin V-APC $(0.1 \mu \mathrm{g} / \mathrm{ml})$ for the assessment of PS exposure, $\mathrm{PI}(0.5 \mu \mathrm{g} / \mathrm{ml})$ for cell viability analysis, and tetramethylrhodamine ethyl ester $(20 \mathrm{nM})$ for $\Delta \Psi \mathrm{m}$ quantification. Cell death was recorded in a FACSCanto II (BD Biosciences, Le Pont-De-Claix, France) in the total population (10000 cells) and data were analyzed using FlowJo software (Tree Star, Ashland, OR, USA).

Determination of ATP content. Cells treated as indicated above were lysed and the total ATP content was assessed with a luciferin-luciferase kit. Luminescence was measured in a Berthold LB96V MicroLumat Plus. ATP content is expressed as relative to the number of cells analyzed in arbitrary units. A value of $100 \%$ refers to the ATP quantified in control cells.

Poly(ADP ribose) assessment. For immunoblotting detection, $1 \times 10^{6}$ cells were lysed in RIPA buffer containing $25 \mathrm{mM}$ Tris- $\mathrm{HCl}(\mathrm{pH} 6.0), 150 \mathrm{mM} \mathrm{NaCl}, 1 \%$ sodium deoxycholate, $0.1 \%$ SDS, and $1 \%$ NP-40. Samples were resolved on 5-8\% SDS-polyacrylamide gels and transferred onto a PVDF membrane using a semidry method. Membrane blocking and antibody incubations were performed in PBS $0.1 \%$ Tween-20 plus $5 \%$ non-fat dry milk. Membranes were probed with an anti-PAR antibody (Clone $10 \mathrm{H}$, Alexis, Illkirch, France), immunoreactive proteins were detected by an HRPconjugated anti-mouse antibody, and revealed by enhanced chemiluminescence (ECL, Pierce, Thermo Fisher Scientific, Brebières, France).

Alternatively, cells seeded on coverslips were fixed in ice-cold methanol for $15 \mathrm{~min}$, permeabilized with $0.1 \%$ Triton X-100, pre-incubated in $10 \%$ goat serum for $30 \mathrm{~min}$, incubated with the anti-PAR antibody, and detected by anti-rabbit $\lg \mathrm{G}$ conjugated with Alexa Fluor 488 (Invitrogen). Before assessment, cells were co-stained with Hoechst 33342 and mounted with FluorSave (Calbiochem, Merck, Darmstadt, Germany). Green and blue fluorescences were recorded in a confocal microscope (LSM-510 Meta, Carl Zeiss France, Le Pecq, France). Quantification was performed on 150 cells for each data point.

Calpain activity. Calpain activity present in $30 \mu \mathrm{g}$ of total-cell lysates was determined by cleavage of the fluorescent substrate $\mathrm{N}$-succinyl-LLVY-AMC (Calbiochem) and expressed as the difference between calcium-dependent and calcium-independent fluorescence. Calcium-dependent fluorescence was measured after $30 \mathrm{~min}$ incubation at $37^{\circ} \mathrm{C}$ in buffer containing $63 \mathrm{~mm}$ imidazole$\mathrm{HCl}(\mathrm{pH} 7.3), 10 \mathrm{mM} \beta$-mercaptoethanol and $5 \mathrm{mM} \mathrm{CaCl}_{2}$. Calcium-independent fluorescence was measured under the same conditions using buffer without $\mathrm{CaCl}_{2}$ and containing $1 \mathrm{mM}$ EDTA and $10 \mathrm{mM}$ EGTA. Fluorescence was recorded in a Fluoroskan Ascent Fluorimeter (Labsystems, Eragny-Parc, France).

Calpain activity in live cells was detected using the cell-permeable calpain substrate Boc-Leu-Met-CMAC (Invitrogen). Cells spread on coverslides were incubated for 30 min with $50 \mu \mathrm{M}$ of calpain substrate in DMEM culture medium. Cells were then treated or not with MNNG and observed in a Nikon Eclipse TE2000-U microscope (Nikon France, Champigny-Sur-Marne, France). Quantification was performed on 100 cells for each data point.

BAX activation and redistribution. For flow cytometry or immunofluorescence analysis, cells were fixed in $1 \%$ paraformaldehyde (PFA), permeabilized with $0.1 \%$ saponin for $10 \mathrm{~min}$, incubated for $1 \mathrm{~h}$ with an antibody designed against the active form of BAX (clone 6A7, BD Biosciences, ref. \#556467), and detected by an anti-mouse IgG conjugated with Alexa Fluor 488 or 647 . Cells were either analyzed by cytofluorometry or stained with Hoechst 33342 and incubated with Mitotracker Red before fixation for immunofluorescence assessment. Images were acquired with a confocal microscope as above. Quantification was performed on 100 cells for each data point.

3'-OH DNA breaks (TUNEL) detection. Detection of blunt doublestranded fragments carrying a $5^{\prime}$-phosphate and $3^{\prime}$-hydroxyl group was carried out by fixing cells in freshly prepared $1 \%$ PFA for $30 \mathrm{~min}$ at $4{ }^{\circ} \mathrm{C}$ and permeabilized with $0.1 \%$ Triton X-100 and $0.1 \%$ sodium citrate for $10 \mathrm{~min}$ at $4^{\circ} \mathrm{C}$. After washing in PBS containing $1 \% \mathrm{BSA}$, cells were incubated for $1 \mathrm{~h}$ at $37^{\circ} \mathrm{C}$ with $50 \mu$ lo a reaction mixture containing $0.025 \mathrm{nmol}$ of Fluorescein-12-dUTP (Roche, Meylan, France) or CF 640R-dUTP (Biotium, Hayward, CA, USA), $0.25 \mathrm{nmol}$ of dATP, $2.5 \mathrm{~mm} \mathrm{CoCl}, 80$ units of recombinant terminal deoxynucleotidyl transferase (TdT) and TdT reaction buffer from Roche. After being washed in PBS, cells were analyzed by flow cytometry.

BID modeling. BID structure (pdb 1DDB) was modeled in SwissPDBViewer (Swiss Institute of Bioinformatics, Lausanne, Switzerland) and the resulting model was edited with Pymol (Delano Scientific, San Carlos, CA, USA), as previously described. $^{14}$

Single cell gel electrophoresis (COMET). Neutral comet assay was performed with a kit from Trevigen following the manufacturer's instructions. Single-cell images were captured and analyzed using a Nikon Eclipse TE2000-U microscope as indicated above. Quantification was performed on 100 cells for each data point.

MTT cell viability. 3-(4,5-Dimethylthiazol-2-y)-2,5-diphenyltetrazolium bromide (MTT, $0.5 \mathrm{mg} / \mathrm{ml}$ final concentration) was added to the culture medium of cells growing in 96-well dishes (6000 cells/well). After incubating the dishes at $37^{\circ} \mathrm{C}$ for $90 \mathrm{~min}$, the assay was stopped by adding $100 \mu \mathrm{l}$ DMSO. Formazan salts were allowed to dissolve in DMSO shaking them gently for $10 \mathrm{~min}$ at room temperature (RT), and the assays were quantified by means of a Multiskan plate reader (ThermoLabsystems, Cergy Pontoise, France). Final values were the result of subtracting $630 \mathrm{~nm}$ from $590 \mathrm{~nm}$ readings.

Cell cycle analysis and BrdU staining. Cells were harvested, washed once in PBS, fixed in ice-cold ethanol, and kept at $-20^{\circ} \mathrm{C}$. DNA contents were assessed by using PI $(20 \mu \mathrm{g} / \mathrm{ml})$ after 20 min incubation with RNAse A $(160 \mu \mathrm{g} / \mathrm{ml})$.

To determine DNA synthesis, cells were pulse-labeled with $30 \mu \mathrm{M}$ BrdU for $30 \mathrm{~min}$. Cells were fixed for at least $16 \mathrm{~h}$ and membranes were digested with $0.05 \%$ pepsin in $30 \mathrm{mM} \mathrm{HCl}$ at $37^{\circ} \mathrm{C}$ for $20 \mathrm{~min}$. To allow the access of anti-BrdU antibody to the incorporated BrdU, DNA denaturation by $2 \mathrm{~N} \mathrm{HCl}$ was performed for $20 \mathrm{~min}$ at RT. Following centrifugation, acid was neutralized by adding $0.1 \mathrm{M}$ sodium borate for $4 \mathrm{~min}$. Cells were then centrifuged, washed, and FITC-conjugated anti-BrdU antibody (BD Biociences) was added for $45 \mathrm{~min}$ at RT. The incubation buffer used was $20 \mathrm{mM}$ HEPES, $0.5 \%$ FCS, $0.5 \%$ Tween-20. DNA was stained with PI before flow cytometer analysis. 
Protein extraction, cell fractionation, immunoblotting. For whole-protein extracts, $1 \times 10^{6}$ cells were lysed in buffer containing $20 \mathrm{~mm}$

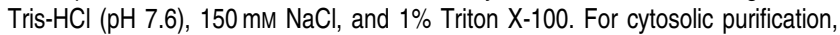
$2 \times 10^{6}$ cells were resuspended in buffer containing $220 \mathrm{mM}$ mannitol, $70 \mathrm{mM}$ sucrose, $50 \mathrm{~mm}$ Hepes-KOH (pH 7.2), $10 \mathrm{~mm} \mathrm{KCl}, 5 \mathrm{~mm} \mathrm{EGTA}, 2 \mathrm{~mm} \mathrm{MgCl}$, and $0.025 \%$ digitonin, and kept on ice for $5 \mathrm{~min}$. Lysed cells were centrifuged $\left(16000 \times \mathrm{g}, 5 \mathrm{~min}, 4^{\circ} \mathrm{C}\right)$ and the supernatant was retained as cytosolic fraction. Mitochondrial fractions were obtained using the Mitochondria Isolation kit from Pierce following the manufacturer's instructions. Protein concentration was determined using the BioRad protein assay. Equal amounts of total proteins $(40-100 \mu \mathrm{g})$ were loaded on $4-12 \%$ NuPAGE or linear SDS-PAGE gels and transferred onto a PVDF membrane. Membrane blocking and antibody incubations were performed in PBS $0.1 \%$ Tween-20 plus $5 \%$ non-fat dry milk. The primary antibodies used were: BAX (specific for BAX p18 detection, BD Biosciences), AIF, BID/tBID (clone 14F2 Novus Biologicals, Cambridge, UK or AF860 R\&D Systems, Lille, France), phospho BIDS78, phospho BIDS61 (Bethyl, Montgomery, TX, USA), pan-ERK (BD Biosciences), Cox IV subunit VIb (Invitrogen), V5 (clone V5-10), or $\beta$-actin (clone AC-15). Immunoreactive proteins were detected using HRPconjugated secondary antibodies and revealed by the ECL system. In some experiments, equal loading was confirmed by staining the membrane with naphtol blue. Immunoblot images were acquired in a Bio-Imaging System MF-ChemiBis 4.2 (FSVT, Courbevoie, France) or in a Kodax X-OMAT 1000 processor (Kodak, Chalon-Sur-Saone, France).

Statistics. Statistical analysis was carried out using the student's $t$-test.

Chemicals and reagents were purchased from Sigma-Aldrich except where otherwise noted.

\section{Conflict of Interest}

The authors declare no conflict of interest.

Acknowledgements. We are grateful to Drs. SJ Korsmeyer, NN Danial, DCS Huang, PA Greer and MA Kelliher for immortalized MEFs, RS Moubarak for preliminary data, and $M$ Segade for proofreading. This work was supported by Agence Nationale de la Recherche (ANR; contract ANR-09-BLAN-0247), Association pour la Recherche sur le Cancer (ARC; contracts 5104 and 7987), Ligue Contre le Cancer, and Fondation de France (to SA Susin). L Cabon received a $\mathrm{PhD}$ fellowship from École Normale Supérieure de Cachan (ENS-Cachan).

1. Kerr JF, Wyllie AH, Currie AR. Apoptosis: a basic biological phenomenon with wide-ranging implications in tissue kinetics. Br J Cancer 1972; 26: 239-257.

2. Hengartner MO. The biochemistry of apoptosis. Nature 2000; 407: 770-776.

3. Jaattela M. Programmed cell death: many ways for cells to die decently. Ann Med 2002; 34: $480-488$.

4. Festjens N, Vanden Berghe T, Vandenabeele P. Necrosis, a well-orchestrated form of cell demise: signalling cascades, important mediators and concomitant immune response. Biochim Biophys Acta 2006; 1757: 1371-1387.

5. Vandenabeele P, Galluzzi L, Vanden Berghe T, Kroemer G. Molecular mechanisms of necroptosis: an ordered cellular explosion. Nat Rev Mol Cell Biol 2010; 11: 700-714.

6. Delavallee L, Cabon L, Galan-Malo P, Lorenzo HK, Susin SA. AIF-mediated caspaseindependent necroptosis: a new chance for targeted therapeutics. IUBMB Life 2011; 63: 221-232.

7. Xu Y, Huang S, Liu ZG, Han J. Poly(ADP-ribose) polymerase-1 signaling to mitochondria in necrotic cell death requires RIP1/TRAF2-mediated JNK1 activation. J Biol Chem 2006; 281: 8788-8795.

8. Moubarak RS, Yuste VJ, Artus C, Bouharrour A, Greer PA, Menissier-de Murcia $\mathrm{J}$ et al. Sequential activation of poly(ADP-ribose) polymerase 1, calpains, and Bax is essential in apoptosis-inducing factor-mediated programmed necrosis. Mol Cell Biol 2007; 27: 4844-4862.

9. Susin SA, Lorenzo HK, Zamzami N, Marzo I, Snow BE, Brothers GM et al. Molecular characterization of mitochondrial apoptosis-inducing factor. Nature 1999; 397: 441-446.

10. Norberg E, Orrenius S, Zhivotovsky B. Mitochondrial regulation of cell death: processing of apoptosis-inducing factor (AIF). Biochem Biophys Res Commun 2010; 396: 95-100.

11. Cregan SP, Fortin A, MacLaurin JG, Callaghan SM, Cecconi F, Yu SW et al. Apoptosisinducing factor is involved in the regulation of caspase-independent neuronal cell death. $J$ Cell Biol 2002; 158: 507-517.

12. Zhu C, Wang X, Huang Z, Qu L, Xu F, Vahsen $N$ et al. Apoptosis-inducing factor is a major contributor to neuronal loss induced by neonatal cerebral hypoxia-ischemia. Cell Death Differ 2007; 14: 775-784.
13. Culmsee C, Zhu C, Landshamer S, Becattini B, Wagner E, Pellecchia M et al. Apoptosisinducing factor triggered by poly(ADP-ribose) polymerase and Bid mediates neuronal cell death after oxygen-glucose deprivation and focal cerebral ischemia. J Neurosci 2005; 25: 10262-10272.

14. Artus C, Boujrad H, Bouharrour A, Brunelle MN, Hoos S, Yuste VJ et al. AlF promotes chromatinolysis and caspase-independent programmed necrosis by interacting with histone H2AX. EMBO J 2010; 29: 1585-1599.

15. Baritaud M, Boujrad H, Lorenzo HK, Krantic S, Susin SA. Histone H2AX: the missing link in AIFmediated caspase-independent programmed necrosis. Cell Cycle 2010; 9: 3166-3173.

16. Chipuk JE, Moldoveanu T, Llambi F, Parsons MJ, Green DR. The BCL-2 family reunion. Mol Cell 2010; 37: 299-310.

17. Martinou JC, Green DR. Breaking the mitochondrial barrier. Nat Rev Mol Cell Biol 2001; 2: 63-67.

18. Boujrad H, Gubkina O, Robert N, Krantic S, Susin SA. AIF-mediated programmed necrosis: a highly regulated way to die. Cell Cycle 2007; 6: 2612-2619.

19. Gao G, Dou QP. N-terminal cleavage of Bax by calpain generates a potent proapoptotic $18-\mathrm{kDa}$ fragment that promotes bcl-2-independent cytochrome $\mathrm{c}$ release and apoptotic cell death. J Cell Biochem 2000; 80: 53-72.

20. Tan Y, Dourdin N, Wu C, De Veyra T, Elce JS, Greer PA. Ubiquitous calpains promote caspase-12 and JNK activation during endoplasmic reticulum stress-induced apoptosis. J Biol Chem 2006; 281: 16016-16024.

21. Donovan N, Becker EB, Konishi Y, Bonni A. JNK phosphorylation and activation of BAD couples the stress-activated signaling pathway to the cell death machinery. J Biol Chem 2002; 277: 40944-40949.

22. Putcha GV, Le S, Frank S, Besirli CG, Clark K, Chu B et al. JNK-mediated BIM phosphorylation potentiates BAX-dependent apoptosis. Neuron 2003; 38: 899-914.

23. Chen M, He H, Zhan S, Krajewski S, Reed JC, Gottlieb RA. Bid is cleaved by calpain to an active fragment in vitro and during myocardial ischemia/reperfusion. J Biol Chem 2001; 276: 30724-30728.

24. Landshamer S, Hoehn M, Barth N, Duvezin-Caubet S, Schwake G, Tobaben S et al. Bidinduced release of AIF from mitochondria causes immediate neuronal cell death. Cell Death Differ 2008; 15: 1553-1563.

25. Tobaben S, Grohm J, Seiler A, Conrad M, Plesnila N, Culmsee C. Bid-mediated mitochondrial damage is a key mechanism in glutamate-induced oxidative stress and AIF-dependent cell death in immortalized HT-22 hippocampal neurons. Cell Death Differ 2010; 18: 282-292.

26. Kamer I, Sarig R, Zaltsman Y, Niv H, Oberkovitz G, Regev L et al. Proapoptotic BID is an ATM effector in the DNA-damage response. Cell 2005; 122: 593-603.

27. Zinkel SS, Hurov KE, Ong C, Abtahi FM, Gross A, Korsmeyer SJ. A role for proapoptotic BID in the DNA-damage response. Cell 2005; 122: 579-591.

28. Gross A, Yin XM, Wang K, Wei MC, Jockel J, Milliman C et al. Caspase cleaved BID targets mitochondria and is required for cytochrome $c$ release, while $B C L-X L$ prevents this release but not tumor necrosis factor-R1/Fas death. J Biol Chem 1999; 274: 1156-1163.

29. Li H, Zhu H, Xu CJ, Yuan J. Cleavage of BID by caspase 8 mediates the mitochondrial damage in the Fas pathway of apoptosis. Cell 1998; 94: 491-501.

30. Cartron PF, Gallenne T, Bougras G, Gautier F, Manero F, Vusio P et al. The first alpha helix of Bax plays a necessary role in its ligand-induced activation by the $\mathrm{BH}$-only proteins Bid and PUMA. Mol Cell 2004; 16: 807-818.

31. Giam M, Huang DC, Bouillet P. BH3-only proteins and their roles in programmed cell death. Oncogene 2008; 27 (Suppl 1): S128-S136.

32. Walensky LD, Pitter K, Morash J, Oh KJ, Barbuto S, Fisher J et al. A stapled BID BH3 helix directly binds and activates BAX. Mol Cell 2006; 24: 199-210.

33. Tompa P, Buzder-Lantos P, Tantos A, Farkas A, Szilagyi A, Banoczi Z et al. On the sequential determinants of calpain cleavage. J Biol Chem 2004; 279: 20775-20785.

34. Mandic A, Viktorsson K, Strandberg L, Heiden T, Hansson J, Linder S et al. Calpainmediated Bid cleavage and calpain-independent Bak modulation: two separate pathways in cisplatin-induced apoptosis. Mol Cell Biol 2002; 22: 3003-3013.

35. Sarig R, Zaltsman Y, Marcellus RC, Flavell R, Mak TW, Gross A. BID-D59A is a potent inducer of apoptosis in primary embryonic fibroblasts. J Biol Chem 2003; 278: 10707-10715.

36. Polster BM, Basanez G, Etxebarria A, Hardwick JM, Nicholls DG. Calpain I induces cleavage and release of apoptosis-inducing factor from isolated mitochondria. J Biol Chem 2005; 280: 6447-6454.

37. Vittar NB, Awruch J, Azizuddin K, Rivarola V. Caspase-independent apoptosis, in human MCF-7c3 breast cancer cells, following photodynamic therapy, with a novel water-soluble phthalocyanine. Int J Biochem Cell Biol 2010; 42: 1123-1131.

38. Zaltsman Y, Shachnai L, Yivgi-Ohana N, Schwarz M, Maryanovich M, Houtkooper RH et al. MTCH2/MIMP is a major facilitator of tBID recruitment to mitochondria. Nat Cell Biol 2010; 12: 553-562.

39. Hitomi J, Christofferson DE, Ng A, Yao J, Degterev A, Xavier RJ et al. Identification of a molecular signaling network that regulates a cellular necrotic cell death pathway. Cell 2008; 135: 1311-1323.

40. Burton TR, Gibson SB. The role of Bcl-2 family member BNIP3 in cell death and disease: NIPping at the heels of cell death. Cell Death Differ 2009; 16: 515-523. 